\title{
Complicated Upper Urinary Tract Infection
}

\author{
Nasser Shakhssalim ${ }^{1}$, Mohammad Samzadeh² \\ and Seyed Mohammad Ghahestani ${ }^{3}$ \\ ${ }^{1}$ Assistant Professor of Urology, Urology and Nephrology Research Center (UNRC), \\ Shahid Labbafinejad Medical Center, Shahid Beheshti University of \\ Medical Sciences (SBUMS), Tehran, \\ ${ }^{2}$ Resident of Urology, UNRC, Shahid Labbafinejad Medical Center,SBUMS, Tehran, \\ ${ }^{3}$ Fellowship of Pediatric Urology \\ Tehran university of medical sciences(TUMS), Children Medical Center Hospital \\ I.R. Iran
}

\section{Introduction}

A renal abscess is an accumulation of pus inside renal parenchyma. The presence of pus can be substantiated by means of imaging or percutaneous aspiration. When we say pus, we usually mean liquefaction while there is also another entity we can call a gaseous abscess resembling emphysematous pyelonephritis in imaging, but following a more benign course such as a localized renal abscess [1].

\subsection{Pathophysiology}

A host of organisms may cause a renal abscess. There seems to be a chronological shift of organisms from staphylococci to Gram negatives since 25 years ago with prevailing use of antibiotics.[2] Currently, the most common organisms are E. coli, Klebsiella pneumoniae, Pseudomona aeruginosa and Staphylococcus aureus [3]. Other unusual organisms are likely and clinical background should raise the suspicion e.g. Salmonella parathyphi A [4], Salmonella typhimurium [5], Nocardia [6], Morganella morganii [7], Streptococcus group B [8], Serratia marcescens [9]. In immunocompromised and AIDS patients, other opportunistic organisms like Aspergillus fumigatus [10] and Mycobacterium avium complex [11] may also be involved. Special clinical scenarios must raise suspicion toward specific organisms. Endophthalmitis accompanied by renal abscess has been reported with Klebsiella pneumonia and Serratia marcescens $[9,12]$. In one case, Salmonella virchow phage type 1 renal abscess was reported in association with pelvis transitional cell carcinoma [13]. Renal abscess may also happen as a consequence of infective endocarditis metastasis [14].

Predisposing factors are diabetes mellitus, urolithiasis, immunosuppression [15] and vesicoureteral reflux [16-19]. Nevertheless, it may happen in previously healthy people [20, 21].

\subsection{Clinical presentation}

Although fever, nausea and vomiting, abdominal and flank pain are cited as usual clinical features [3], yet in some instances the symptoms may be insidious and nonspecific [19, 22]. Disguised clinical presentations must not be ignored since renal abscess with infectious 
metastases to the lung has been mistaken with Wilm's tumor [22]. Acute peritonitis as first manifestation of a renal abscess has also been reported.[23]Endophthalmitis associated with renal abscess and klebsiella pneumonia[12, 23, 24] and Serratia marcescens [9] was mentioned. Renal abscess has also been reported in accompaniment with transitional cell carcinoma [25] and renal cell carcinoma [13, 25, 26] in the same kidney so a nonresolving mass must be approached with suspicion.

It looks that renal abscess has a high potential for infectious metastasis reasonably justified by high vascularity of the kidney; hence, a whole body physical exam must never be underrated.

\subsection{Paraclinic findings}

In a series of pediatric patients, urine culture was positive in $60 \%$ and blood culture was positive in only $2 \%$.[3]. In another series, less than half of the patients had either an abnormal urinalysis or urine culture [17]. Thus, there is a high likelihood of negative urine and blood cultures. Leukocytosis is common [17] and elevated blood urea and creatinine have been linked with poorer prognosis [15].

Sonography is undoubtedly a very useful and accessible tool for detecting renal pathologies, but there are still some doubts on its reliability as the sole diagnostic tool for detecting and confirming a renal abscess. It seems wise to use sonography as a screening tool and then proceed to CT scan if any mass or nephromegaly is seen. The inclusion of nephromegaly as a criterion to perform a computerized tomography seems to increase the sensitivity of sonography [3]. Actually, we may see a hypoechoic or anechoic mass or nephromegaly. There may also be debris inside the mass moving in the position changes [27]. CT must also be performed in those patients with normal sonogram, but discordant clinical behavior (lack of response to antibiotics, infectious metastases, papillary necrosis, etc), or if there remains any doubt in diagnosis based on sonography.

$\mathrm{CT}$ is the most accurate modality for detecting a renal abscess [27]. An abscess usually appears as a well-defined low-density mass. An irregular and thick wall or pseudocapsule is better imaged after contrast enhancement [28, 29]. A separately defined entity called gaseous abscess can also be effectively diagnosed by CT. On CT, gas-forming renal abscesses appear as discrete gas pockets without purulent material within the renal parenchyma. The interesting point is that in this entity, despite emphysematous pyelonephritis gas persisted to exist in images several months after treatment [1]. In CT, gas has a HU number $\leq-150$ but liquid $\pm 10 \mathrm{HU}$ [27]. Although, Inidium 111 and Gallium isotope scans may have a role in diagnosis, but false negative results have been reported [30]. These scans may be particularly useful when the location of infectious intra abdominal process is still unknown.

In children with a history of febrile urinary infection, performing a MCUG must not be neglected. Not only this helps to detect vesicoureteral reflux, but also reveals many unsuspected bladder outlet and urethral pathologies. A DMSA scan 6 to 12 months later can show the extent of damage to renal parenchyma [3].

\subsection{Management}

The treatment of renal abscess has changed from open intervention to percutaneous drainage and intravenous antibiotic therapy. In a retrospective but critical analytic study, abscesses less than $3 \mathrm{~cm}$ in diameter responded well to antibiotic therapy, those between 3 
and $5 \mathrm{~cm}$ responded $92 \%$ to single percutaneous treatment (using either sonography or CT guidance), and in abscesses above $5 \mathrm{~cm}$ responded to multiple drainages (alternatively a temporary indwelling pigtail) and antibiotic treatment.[31]. Percutaneous treatment seems as effective as open surgical drainage [31,32]. The presence of immunocompromised state must push us one step forward to a more aggressive approach. The choice of antibiotic in cases of percutaneous drainage can best be based on aspirate culture results. In non-drained cases, positive urine culture can guide the treatment that an empirical regimen covering both Gram-negative enteric bacteria and staphylococci can be used otherwise. In small abscesses which do not respond to antibiotics in a timely manner, a percutaneous drainage can be both curative and diagnostic.

Three to six weeks of parenteral and oral antibiotic may be necessary [3], but the duration of antibiotic treatment and time of switching to oral treatment must be based on clinical response and sonographic follow up. As previously cited, concomitance with renal malignancies have been reported thus lack of adequate response to treatment must raise a suspicion.

\section{Perinephric abscess}

\subsection{Introduction}

Perinephric abscess refers to accumulation of pus inside Gerota's fascia. There may also be gas bubbles especially in diabetics due to glucose fermentation [33] and this should not be mistaken with separate entity of emphysematous pyelonephritis.

The incidence ranges from 1 to 10 cases for every 10,000 hospital admissions. Men and women are affected with equal frequency. [33] In a population based cohort retrospective study in an eleven-year follow-up period [34] the incidence rates for the diabetics and the control subjects were 4.6 and 1.1/10000 person-years, respectively, representing an adjusted hazard ratio of 3.81 (95\% confidence interval $3 \cdot 44-4 \cdot 23)$. Therefore, diabetes mellitus in an immunocompromised setting stands as a major predisposing factor.

\subsection{Pathophysiology}

Most of perinephric abscesses are caused by ascending enteric Gram-negative bacteria.[35]. In a study of 26 cases, $67 \%$ of cultures yielded enteric Gram-negative bacteria[36], however, metastatic staphylococcal infections still happen [33].This entity may also follow the chronological shift of causative organism of renal abscess. A host of other unusual bacteria have also been reported. Among those, Shigella flexneri [37], Stenotrophomonas maltophilia [38], Nocardia [39] group B streptococcus [40], Candida glabrata [41], Aspergillus fumigates [42], Listeria monocytogenes [43], coagulase-negative Staphylococcus [44], Salmonella [45], Torulopsis glabrata [46, 47], Bacteroides fragilis [48] and Trichomonas vaginalis [49] have been reported to cause perinephric abscess in non-transplant patients. Mycoplasma hominis [50], Streptococcus agalactiae [51], Nocardia[52], and Gardnerella vaginalis[53] have been reported to cause perinephric abscess in patients with kidney graft. In a review of kidney transplant patients with perinephric abscess, staphylococci with a prevalence of $36 \%$, and aerobic Gramnegative rods with a prevalence of $32 \%$ were the most common pathogens. Also of note were the presence of anaerobes (28\%) and candida albicans (4\%) [54].

There are also predisposing conditions strongly related with development of perinephric abscess. In a study on 23 patients, the predisposing conditions were identified as follows: diabetes mellitus in $65.2 \%$, history of nephrolithiasis in $43.47 \%$, and the history of urological 
surgery in $17.38 \%$ [55]. In some older series (1977) diabetes had a smaller role, and the main role was attributed to nephrolithiasis $(76 \%)$ [36].

Some special conditions have been described in accompaniment or as a cause of perinephric abscess: urinary extravasation associated with renal colic [56], colon carcinoma [57],renal cell carcinoma [58], extracorporeal shockwave lithotripsy [59-61], splenic abscess [62, 63], and ruptured retrocecal appendicitis [64,65]. One must not ignore these conditions in the management of a perinephric abscess.

\subsection{Clinical presentation}

It may either present as an insidious disease or an acute process. Ascending infections have been described to follow an insidious course, but metastatic staphylococcal abscesses may show a dramatic course [33]. Yeast abscesses have been described to follow a chronic course with nonspecific symptoms that the usual culprits are Candida and Torulopsis species [66]. A patient with perinephric abscess has been presented with just a chronic diarrhea and weight loss [67]. Therefore, in most cases a high level of suspicion is necessary to proceed to appropriate imaging modalities. Unusual presentations as acute peritonitis [68, 69], acute pancreatitis [70], and fulminant hepatic failure [71] have been described too. A subcutaneous abscess in the loin may root in a perinephric abscess [72]. Nephrobronchial fistula may happen in the context of an unknown perinephric abscess; hence, if a patient presents perirenal suppurative process with the chest $x$-ray findings consistent with pleural effusion or pulmonary infiltrates, perinephric abscess have to be considered in differential diagnosis along with malignancy [73].

\subsection{Paraclinic findings}

Aspirate cultures are undoubtedly the best guide for antibiotic treatment. Laboratory findings have also been correlated with prognosis and outcome.

In a retrospective study recruiting 23 patients, hemoglobin levels and white blood cells counts were associated with the loss of the renal unit, thrombocytopenia was linked with septic shock, and hyponatremia with mortality [55].

In this study, a hemoglobin concentration greater than $10.5 \mathrm{~g} / \mathrm{dl}$ and a white blood cell count lower than $15 \times 10(3)$ / microL were associated with nephrectomy, and a platelet count lower than $140 \times 10(3)$ / microL with septic shock. General mortality was $8.69 \%$, and $78.3 \%$ of patients required nephrectomy. Patients who died had fever, anemia, a white blood cell count greater than $16 \times 10(3) /$ microL, platelet count lower than $130 \times 10(3)$ / microL, and hyponatremia of $125 \mathrm{mEq} / \mathrm{L}$ or lower at hospital admittance, and all of them had septic shock that required nephrectomy.

Sonography alone may have a substantial risk of incorrect or missed diagnosis. In a study, perinephric abscesses which were not seen in ultrasonography were those associated with pyonephrosis, abscesses smaller than $6 \mathrm{~cm}$ and gas-forming abscesses [74]. Although sonography has an important role as a non-ionizing accessible tool of first investigation, it could be misleading in some cases. One should not hesitate performing a CT scan in cases of urinary tract infection with an unusual course or resistant to antibiotic treatment with normal sonography. In another study, sonography failed to show abscesses smaller than 2-3 Cm.

CT scan has also the advantage of detecting concomitant pathologies cited before. As nephrolithiasis has been cited as a major predisposer, the investigation must be completed both with and without contrast for optimal results. Gallium-67 scintigraphy appears to be useful in detecting perinephric abscess in patients with polycystic kidney disease undergoing chronic hemodialysis [75]. 


\subsection{Management}

Antibiotic treatment must be guided by urine, blood or aspirate culture. Before the culture results get ready, a regimen covering both Gram-negative enteric bacteria and staphylococci is usually adopted. However, the mainstay of treating a perinephric abscess is drainage [33]. A percutaneous approach is preferred in most cases unless in multilocular, very large abscesses with extremely viscous purulent material in which open drainage is necessary. Laparoscopic treatment has been reported [76], but evidently it has not been introduced as a standard method yet.

Controlling diabetes mellitus or any underlying condition is mandatory. A urinary obstruction must be dealt with by either a percutaneous stent, or double J stent, or open intervention. In blood dyscrasias recombinant human granulocyte colony-stimulating factor may be helpful [77]. Unusual causative or accompanying conditions cited before must be cautiously addressed. Hematuria is uncommon in cases of perinephric abscess. When hematuria is present in a patient with perinephric abscess further evaluation is necessary to rule out an associated malignant process [58].

\section{Spectrum of infected hydronephrosis and pyonephrosis}

\subsection{Introduction}

Infected hydronephrosis denotes bacterial infection in a hydronephrotic kidney. Pyonephrosis occurs when suppurative destruction of parenchyma has begun. By definition, both conditions occur in obstructed kidneys. The level of obstruction varies from a calyceal infundibulum (pyocalyx) to bladder outlet (pyocystitis/pyonephrosis).

\subsection{Pathophysiology}

The same organisms responsible for acute pyelonephritis may infect a hydronephrotic kidney and ultimately lead to pyonephrosis. Staphylococcus aureus, Mycobacterium tuberculosis, Candida albicans and Anaerobes are other putative organisms [78-80]. The etiology of obstruction may also vary and must be differentiated on the context of patient's age and medical history. One must consider that in many cases there may be a disparity between voided urine culture and pelvis urine culture aspirated by needle or nephrostomy; hence, the best antibiotic regimen must cover both organisms after the aspirate from pelvis is obtained [81].

\subsection{Clinical presentation}

A patient with these conditions have usually fever and chills, loin pain(in almost all), CVA tenderness, lower urinary tract symptoms $(48 \%)$, and palpable renal mass (58\%)[82]. In a study, an initial body temperature of above 38.5 degrees Celsius $(\mathrm{P}=0.0004)$ and an elevated BMI $(\mathrm{P}=0.002)$ were connotative as predictors of urosepsis. [83] However, occasionally the symptoms may be vague or even totally absent [84].The author draws your attention to a case of pyocalyx which may only have a lost calyx in EXU without clinical symptoms of infection where an inappropriate ESWL to treat a stone may cause sepsis and eventual death (unpublished data).

\subsection{Paraclinic findings}

As previously stated, blood culture, voided urine, and pelvis aspirate guides the antibiotic treatment. CRP and ESR were used to differentiate between the infected hydronephrosis and pyonephrosis with a cut-off at $3 \mathrm{mg} / \mathrm{dl}$ for CRP and $100 \mathrm{~mm} / \mathrm{hr}$ for ESR as useful adjuncts for sonographic studies [85]. Cr and blood biochemistry leads to treatment in cases 
of bilateral obstruction or functional solitary kidneys. The role and presence of predisposers like diabetes or immunocompromised states not formerly known must not be overlooked and should be evaluated with appropriate investigations.

In patients with clinical suspicion of renal infection, sonography has an accuracy of up to 96\%.[86]. Sonography can distinguish internal echoes inside the pelvicalyceal system or areas of decreased echogenicity inside parenchyma. As previously said, combining sonography findings with CRP and ESR may further increase the accuracy of differentiating between infected hydronephrosis and pyonephrosis.

MRI with diffusion-weighted images (MRI Dw) and Apparent Diffusion Coefficient (ADC) are helpful to distinguish between infected hydronephrosis and pyonephrosis[87].The extremely low ADC of the renal pelvis of the pyonephrotic kidney accounts for its signal hyperintensity on diffusion-weighted images as well as signal hypointensity on ADC maps. However, the decision to use MRI must be based on the fact that whether or not it could change the treatment strategy. Other modalities may be used to discover the etiology of obstruction e.g. a spiral non-contrast CT may be the best tool to detect an obstructive ureteral stone.

One must avoid using a retrograde pyelography as it increases the internal pressure of an obstructed infected system and may cause urosepsis. Therefore, $t$ should only be done after the infection has been eradicated. In addition to relieving the obstruction in the acute phase, percutaneous nephrostomy provides the opportunity of antegrade pyelography afterwards. Hence, one can have a near physiologic dynamic image while maintaining a safety valve.

\subsection{Management}

Starting antibiotic treatment and relieving obstruction in an obstructed infected kidney are urgent. One starts antibiotic empirically covering Gram-negatives, anaerobes, and staphylococci, and then tailors the regimen according to the aspirate culture. Percutaneous nephrostomy has proved to be an ideal option for obstruction relief in multiple case series including a prospective study while gaining a reliable culture and providing access for subsequent imaging[88-91]. A considerable disparity has been found between the results of the pelvis aspirate and the voided urine culture.[81]Nevertheless, the choice of the method for relieving obstruction must be astutely individualized. In a pelvic kidney with overlying bowel, percutaneous nephrostomy is no longer the ideal first line option and a retrograde stent may be preferred if proved feasible. In a child with duplex system and upper moiety pyonephrosis, upper moiety cutaneous pyelostomy may be performed. For an irreversibly non-functional kidney with a thin parenchyme, a primary nephrectomy may be curative. In many cases, a strict differentiation between infected hydronephrosis and pyonephrosis does not seem to radically change the treatment strategy.

\section{Acute focal bacterial nephritis (AFBN) or lobar nephronia}

\subsection{Introduction}

Acute focal bacterial nephritis (AFBN) or acute lobar nephronia represents as an acute localized non-liquefactive infection of the kidney caused by bacterial infection [92]. This stipulates that the mass should not contain drainable pus. Actually, it is a precursor step to a frank renal abscess before liquefaction. In a study by Klar et al. (1993), of 210 pediatric patients admitted to hospital with manifestations of urinary tract infection, 13 had AFBN. 
Evolution to renal abscess happened in $25 \%$, but all responded well to antibiotic therapy [93]. However, it looks that incidence rate may vary according to the ease of access to medical facilities and cultural background that may alter the interval between the commencement of manifestations of the acute pyelonephritis and the time that antibiotic therapy is instituted.

\subsection{Pathophysiology}

The same process that causes acute pyelonephritis may evolve into AFBN and eventually abscess. In children, both hematogenous [94] and ascending routes [16] have been suspected. Congenital urologic abnormalities especially vesicoureteral reflux has been linked with AFBN. Unusual and fastidious organisms e.g. brucellosis especially in endemic areas must be kept in mind [95]. Diabetes mellitus is a major predisposing factor in all complicated urinary tract infections [96].

\subsection{Clinical presentation}

Clinical manifestations are similar to acute pyelonephritis, but probably in a more severe and durable form. Fever, chills and costovertebral angle tenderness along with signs and symptoms of SIRS(Systemic Inflammatory Response Syndrome) could happen [92]. However, atypical and imitating clinical pictures may happen as nephrectomy with a misdiagnosis of renal tumoral mass has been reported; hence, the condition has also been referred to as renal inflammatory pseudotumor [97].

\subsection{Paraclinic findings}

One expects an active urinalysis and a positive urine culture in many cases, but the point is that in some patients these laboratory findings are absent and a high level of suspicion must be put on such cases [94, 98].

The value of sonography in diagnosis of AFBN has been somewhat controversial. Some consider an average accuracy [99] or even low accuracy [100] in sonography that fails to show half and even over the half of the cases. Another study attributes a high accuracy for sonographic findings of nephromegaly and focal mass in a pediatric group of patients with a specificity of $86 \%$ and a sensitivity of up to $95 \%$.[101]. The author thinks one must also consider the chronological evolution of sonographic technology between 1988[99], 1989[100] and 2004([101]. Newer sonographic apparatus may well be relied upon in revealing renal pathologies.

Reported sonographic appearances of AFBN are varied, but are typically described as being echopoor [102], yet at least in one study in 17 patients, the abnormal areas were echogenic in 12 of them, echopoor in three, and of mixed echogenicity in two [102]. In sonographic follow-up, the inflammatory mass may diminish and disappear in 4 weeks. [92].

The most valuable modality for detection of AFBN is computerized tomography [103] used as reference standard to assess other modalities [29]. AFBN in CT is typically hypodense [99] and may help to differentiate them with renal tumors that are most commonly hyperdense. Different patterns could be seen in CT that they have been linked with prognosis and severity of the disease. In a retrospective study, the CT appearance of AFBN was categorized into three groups: Group I: wedge-shaped lesions (focal or diffuse); Group II: focal mass-like lesions; and Group III: diffuse (multifocal) mass-like lesions. 
The clinical features in Group I patients displayed many similarities with those in uncomplicated acute pyelonephritis (APN) responding to antibiotic therapy promptly. Patients in Group II were successfully treated with antibiotics, but had a protracted clinical course with a slower clinical improvement than Group I. Evolution to renal abscess happened, though uncommonly. In comparison, 33\% of the patients in Group III died despite antibiotic therapy[104].

We must not neglect to detect associated anomalies of urinary tract especially vesicoureteral reflux. In children, doing a MCUG is mandatory. In adults, decision to perform a MCUG must be made on the basis of whether VUR can do any further harm or the need for additional intervention.

\subsection{Management}

The mainstay of treatment in AFBN is antibiotics. There is a well-designed RCT to determine the best duration of treatment [105]. In this study, a three-week antibiotic course was clearly superior to a two-week course. The treatment began with parenteral form, and then, switched to oral form 2 to 3 days after defervescence. Antibiotic must be directed against Gram-negative organisms and staphylococci while the culture results are not ready, or in the cases that urine and blood cultures are negative and clinical suspicion is high [94]. As previously stated, patients with diffuse mass-like lesions on CT may have a grave prognosis as $30 \%$ of them may die of the disease [104]. Therefore, one could infer that in such cases a more vigorous approach including surgery has to be considered.

\section{Chronic pyelonephritis}

\subsection{Introduction}

Chronic pyelonephritis is the result of an underlying renal or urinary tract disease with the subsequent repeated renal infection that ends in scarring, atrophy of the kidney, and eventual renal insufficiency [106]. Besides the history of UTIs, complicating defects such as major anatomic anomalies, urinary tract obstruction, nephrolithiasis, renal dysplasia, analgesic abuse, or most commonly, vesicoureteral reflux (VUR) in young children could be detected in patients with end-stage renal disease and chronic pyelonephritis. Nonetheless, it has never been found that renal insufficiency has been caused by non-obstructive uncomplicated UTI alone [107, 108].

There is a gender susceptibility in chronic pyelonephritis as it is twice more common in females than in males; there is also a higher occurrence in infants and young children (younger than 2 years old) than in older children and adults. Although the greatest risk of renal scarring has been reported in young children, additional renal scars could be the result of repeated infections. [109] There is a three-time higher possibility of VUR and chronic pyelonephritis in white children than in African-American children [110]. VUR could be accompanied by UTIs in 30-45\% of children. Moreover, in siblings of patients with chronic pyelonephritis, VUR prevalence rate could reach up to around 35\% [111, 112].

Chronic renal infection can worsen renal impairment significantly in patients with underlying functional or structural urinary tract abnormalities; hence, diagnosis, localization, and treatment of chronic renal infection are crucial to be found by appropriate studies. The diagnosis is made by radiologic or pathologic examination rather than mere clinical presentation. 
In women and in contrary to a $2 \%$ to $5 \%$ prevalence of bacteriuria, pyelonephritis without complications by obstruction or urinary tract malformation does not result in end-stage renal disease [111].

\subsection{Pathology}

In chronic pyelonephritis, the affected kidney in gross is often diffusely shrunk, scarred, and pitted. The scars could be described as Y-shaped, flat, broad-based depressions with redbrown granular bases. Usually, there is a polar scarring with underlying calyceal distortion and blunting with thin parenchyma that the cortico-medullary demarcation is lost [113]. There are microscopic changes that are usually patchy together with an interstitial infiltrate of lymphocytes, plasma cells, and occasional polymorphonuclear cells. Some portions of the parenchyma are probably replaced by fibrosis and although glomeruli may be preserved, periglomerular fibrosis is commonly observed. In parts of the involved areas, glomeruli could be completely fibrosed along with atrophied tubules. At times, leukocytes and hyaline casts are present in the tubules that the latter may resemble the thyroid colloid where the description renal thyroidization is originated [114]. On the whole, the changes are nonspecific that could be seen in toxic exposures, post-obstructive atrophy, hematologic disorders, post irradiation nephritis, ischemic renal disease, and nephrosclerosis too [113].

\subsection{Clinical presentation}

Chronic pyelonephritis is usually asymptomatic in many individuals until it produces renal insufficiency and then the symptoms are similar to those of any other form of chronic renal failure, but they may have a history of frequent UTIs. A strong correlation between renal scarring and recurrent UTIs exists in children [115]. Although the developing kidney appears to be very susceptible to damage, and this susceptibility appears to be age dependent, in adult kidneys, renal scarring induced by UTIs is rare.

If it is believed that a patient's chronic pyelonephritis is an end result of many episodes of acute pyelonephritis, a history of intermittent symptoms of fever, lethargy, flank pain, and dysuria could be extracted. Moreover, there is a poor correlation between urinary findings and the presence of renal infection. Bacteriuria and pyuria as the hallmarks of UTI, are not predictive of renal infection since patients with significant renal infection may have sterile urine if the infection is outside of the collecting system or in case of an obstructed ureter draining the kidney [107].

Chronic pyelonephritis often progress asymptomatically and the diagnosis is usually incidental during the radiologic investigation to evaluate for the complications associated with renal insufficiency, such as hypertension, visual impairments, headaches, fatigue, and polyuria.

Leukocytes or proteinuria may be detected in urinalysis in these patients, but it is likely to be normal. The severity of renal impairment could be reflected by serum creatinine levels. If there is an active infection, urine cultures might be positive.

Differential diagnosis for chronic pyelonephritis includes chronic renal failure, hypertension, nephrolithiasis, pyonephrosis, perinephric abscess, acute pyelonephritis, uremia, tuberculosis, and some tumor-like lesions in the kidney, namely, xanthogranulomatous pyelonephritis, malacoplakia, and lymphoma [116].

Chronic pyelonephritis might cause morbidity and mortality by causing following conditions:(1) focal glomerulosclerosis, (2) proteinuria, (3) progressive renal scarring, (4) hypertension, (5) end-stage renal disease and (6) xanthogranulomatous pyelonephritis 
$(\mathrm{XPN})$ [112]. The rate of XPN occurrence is $8.2 \%$ in such patients and it reaches up to $25 \%$ in patients with pyonephrosis [117].

\subsection{Paraclinic findings}

Asymmetry and irregularity of the kidney outlines or a small and atrophic kidney on the affected side could be easily detected in intravenous pyelogram or CT scan. The characteristic signs include focal coarse renal scarring, atrophy and cortical thinning, hypertrophy of residual normal tissue (which may mimic a mass lesion) with blunting and dilation (clubbing) of one or more underlying calyces $[118,119]$.

In children with gross reflux, voiding cystourethrogram (VCUG) findings may reveal urine reflux into the renal pelvis and ureteral dilatation [112].

Ultrasonography could be used as an alternative that it similarly demonstrates these findings. The best imaging modality to look for renal scarring is DMSA [120]. By providing high-resolution images of the renal cortex, it allows for both qualitative and quantitative characterization of renal injury and impairment. Areas of scarring can be seen as photopenic areas usually at poles $[120,121]$.

Once the radiologic changes of chronic pyelonephritis have been established, it is important to consider that the repeat of imaging is unlikely to come up with further findings[121].

\subsection{Management}

Since the damage caused by chronic pyelonephritis is irreversible, the management of the radiographic evidence of pyelonephritis should be focused on treating the existing infection, preventing future infections, and monitoring and preserving renal function.

Restricting dietary protein intake can decrease progressive renal injury. The course of renal failure progression could be decelerated through regular checking of blood pressure and aggressive blood pressure control. ACE inhibitors are considered to be particularly beneficial in this setting.

Careful antimicrobial susceptibility tests and the selection of the non-nephrotoxic drugs that yield high urine concentrations must be the basis for the treatment of existing infection. Since there is a possible reduction in renal concentrating ability in pyelonephritis, it may impair excretion and concentration of the antimicrobial drug needed to achieve acceptable bactericidal levels in urine. In order to boost the chance of cure and to avoid recurrence, further progression, and renal damage, the duration of the antimicrobial therapy is recommended to be prolonged along with continuous prophylactic antibiotic regimes [122]. There is either an underlying renal (papillary) lesion or a urologic condition such as obstruction or calculus available that increases the susceptibility to the renal damage, thus appropriate nephrologic and urologic evaluation, treatment and prevention should be undertaken to identify and possibly correct these abnormalities.

Nephrectomy could become necessary in case of hypertension or pain for having a large stone burden in a nonfunctioning kidney.

\section{Emphysematous pyelonephritis}

\subsection{Introduction}

Emphysematous pyelonephritis (EPN) is defined as a rare, yet an acute severe necrotizing infection that involves renal parenchyma and its surrounding tissues causing the presence of gas in the renal parenchyma, collecting system or perinephric tissue [123, 124]. 
Kelly and MacCullum reported the first case of disease in 1898 [125], and then, Schultz and Klorfein introduced the term emphysematous pyelonephritis in 1962 [126].

It is considered as a rare disease as only 600 cases have been reported from 1966 to date [127]. According to some authors EPN is suggested when gas is detected within the renal parenchyma or perinephric space, yet it has been defined by several others as gas within the collecting system, parenchyma, perirenal space, or in any of these areas [128].

Gas could be found not only in the site of inflammation in the sub-capsular, perinephric, and pararenal spaces that in some cases, but gas was also detected even in the scrotal sac and spermatic cord [129].

Emphysematous pyelitis is a separate condition and refers to the presence of gas in the collecting systems only and could be secondary to instrumentation of the urinary tract. With proper medical management emphysematous pyelitis has an excellent prognosis; however, EPN requires special attention due to its life-threatening nature either with medical or surgical management.

Gas could be found in other conditions such as urinary endoscopic procedures, genitourinary trauma, communicating fistulas with the gastrointestinal tract, and produced by bacteria within the urinary tract [123].

The most common associated factor in EPN is diabetes mellitus that an uncontrolled DM is present in 95\% of the cases [131] and the next common cause is urinary tract obstruction $[127,130]$ that urinary calculi are usually found to be the cause of obstruction [128].

A glucose-fermenting bacterial infection, impaired host immunity, decreased tissue perfusion, neurogenic bladder, alcoholism, drug abuse, urinary tract obstruction in nondiabetics and anatomic anomaly are considered to be the other reported risk factors in EPN $[123,130,131]$.

With the female to male ratio of 4:1 in most studies, it is clear there is a greater tendency of the disease toward women $[127,131]$ that the reason for the higher incidence in females seems to originate from increased susceptibility to UTI. A urinary tract obstruction raises the risk of developing secondary EPN to as high as 25-40\% [123]. Despite its worldwide spread, it seems to be geographically more common in Asia [127].

\subsection{Pathogenesis}

The mechanism of gas production is the fermentation of the glucose and lactate to carbon dioxide causing necrotizing infection in an appropriate tissue environment and it usually occurs in the presence of the organisms such as E. coli, Klebsiella spp., Proteus spp., gramnegative facultative anaerobic organisms. E. coli is found to be the causative agent in almost $70 \%$ of the reported cases isolated in urine or pus cultures [132]. There is a presence of bacteriemia in over $50 \%$ of the patients with the same organisms as those in urine or pus culture [130].

In addition to the aforesaid organisms, Proteus mirabilis, Klebsiella pneumonia, Group D Streptococcus, coagulase-negative Staphylococcus, and Candida albicans have been reported as the causative agent for EPN too [132].

In pathology, abscess formation, foci of micro- and macro-infarctions, vascular thrombosis, numerous gas-filled spaces and areas of necrosis surrounded by acute and chronic inflammatory cells implying septic infarction could be identified in kidney [130, 133].

\subsection{Clinical presentation}

Most patients are in their forties and fifties [127, 133-135]. The symptoms and signs are similar to pyelonephritis and include dysuria, fever, rigorous nausea, vomiting, and flank pain $[127,129,132]$. 
The other clinical manifestations to be potentially considered are acute renal dysfunction, acid-base disturbances on blood gases, hyperglycemia, thrombocytopenia and impaired consciousness $[129,130,135]$. There may be a rapid progress into septic shock that could even be the presenting feature in patients with severe emphysematous pyelonephritis [130, 132]. Of the most common physical signs, loin tenderness and in some cases crepitus around the renal area and the scrotum may also be felt $[129,130,132]$. In laboratory tests, leucocytosis could be found in $70-80 \%$ of the cases that thrombocytopenia was seen in 15$20 \%$ of the patients $[129,135]$. Since most patients suffer from diabetes mellitus, high blood glucose level is a common finding.

Among other positive findings in EPN, acute renal failure, microscopic or macroscopic hematuria, and severe proteinuria could be counted too [130].

In EPN prognosis, many identified factors affect mortality including a systolic blood pressure of less than $90 \mathrm{mmHg}$, disturbance of consciousness and an increase in serum creatinine level, thrombocytopenia (OR 22.68, 95\% CI 4.4- 16.32) and bilateral EPN (OR 5.36, $95 \%$ CI $1.41-20.33$ ) that both are attributable to dire prognosis. Antibiotic therapy alone has been associated with a higher risk of mortality (OR 2.85, 95\% CI 1.19- 6.81) and it is in comparison to the additional interventions of percutaneous drainage (PCD) of the abscess or nephrectomy [127, 131]. Based on Wan et al. 's classification, EPN Type I, as seen below, has a ominous prognosis and it is due to the fact that a more fulminating clinical course and more extensive parenchymal damage exist [133].

Reportedly, although diabetes mellitus is a common risk factor for EPN, but surprisingly it does not culminate in an increased mortality [odds ratio (OR) 0.32, 95\% CI 0.05-1.99] [133, 136]. There are also no increased risk of higher mortality in EPN with nephrolithiasis, etiologic factors such as E. coli or K. pneumonia [137, 138], age 50 years, female sex, history of UTIs, alcoholism, bacteremia, proteinuria (presence of urine protein greater than $3 \mathrm{gm} / 1$ on at least 2 occasions during admission), retinopathy, and macrohematuria (presence of urine red blood cells of over than 100 per high power field) [131].

\subsection{Paraclinic findings}

As the clinical and the laboratory findings will only point to sepsis of renal origin, emphysematous pyelonephritis is a radiological diagnosis mostly.

In support of the diagnosis, a plain radiograph is indicative of an abnormal gas shadow in the renal bed that an ultrasonography or CT will confirm the presence of intra renal gas to diagnose EPN. CT is considered to have the highest accuracy of $100 \%$, hence, it is proven to be the most reliable diagnostic tool in EP diagnosis [129]. By identifying parenchymal destruction characteristics, it demonstrates the extent of EPN too $[130,133,135]$. Since ultrasound diagnosis is very much dependent on the operator, it is not sufficiently specific when gas-containing lesions are to be characterized. Calculi or bowel gas are the origin of mistakes as gas appears as echogenic foci.

The accuracy of ultrasonography and plain radiograph of the abdomen is around 69 and $65 \%$, respectively, and it necessitates exploiting abdominal CT for the sake of early diagnosis and further management of EPN [127].

By analysis based on CT findings, EPN has been classified into two types by Wan et al. in 1996. [127, 133] According to this classification in type I, there is a renal necrosis with either total absence of fluid content or the presence of a streaky/mottled gas pattern whereas there is a presence of renal or perirenal fluid along with a loculated gas pattern or the presence of gas in the collecting system in type II (Figure 1). Owing to more extensive parenchymal 
necrosis and more fulminating clinical course, type I EPN is associated with worse prognosis [133].
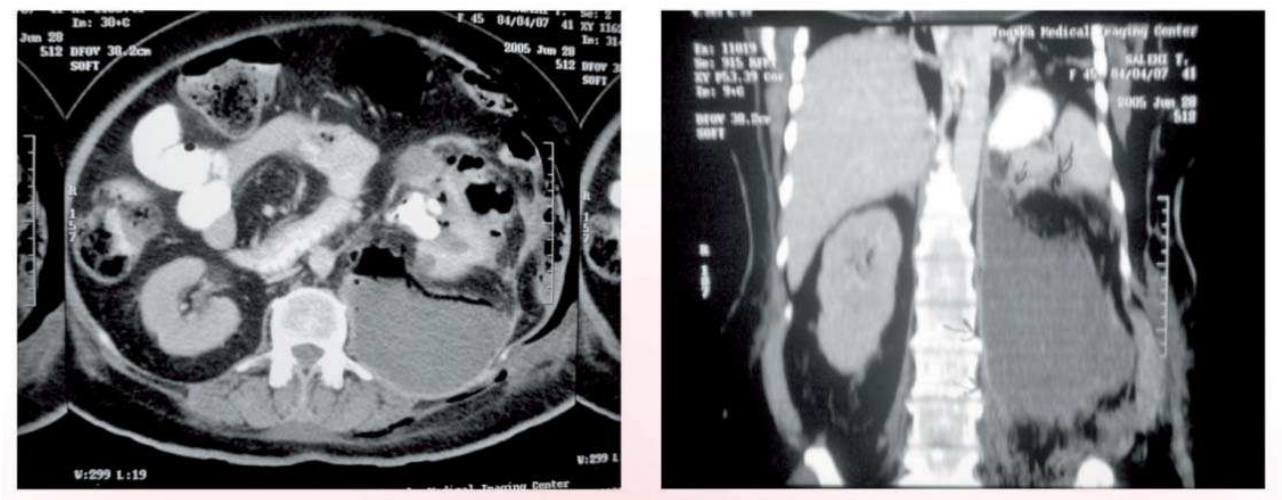

Fig. 1. CT scan showing a large collection with air-fluid level in left retroperitoneal cavity.(transverse and coronal view). ( Courtesy of Simforoosh N., Sharifiaghdas F., Parvin M.,et al. The book "Urology Cases in Practice". Labbafinejad Medical Center, Tehran, Iran.)

In a publication in 2000, Huang and Tseng introduced a new classification based on the CT findings described in more details and with more subcategories that was different to the one mentioned above [130]. Their classification can be summed up as: (1) Class1: the presence of gas in the collecting system only; (2) Class 2: the presence of gas in the renal parenchyma without extension to extrarenal space; (3) Class 3A: extension of gas or abscess to perinephric space; Class 3B: extension of gas or abscess to pararenal space; and (4) Class 4: bilateral EPN or solitary kidney with EPN.

The purpose of such detailed classification by Huang and Tseng was to show the correlation between the EPN classification and its management.

Nonetheless, the described classification by Wan et al. has been evaluated for the risk factors and the management of EPN in two published meta-analyses.

\subsection{Management}

In those patients under the treatment for pyelonephritis, the radiological diagnosis of Emphysematous Pyelonephritis could be overlooked unless appropriate imaging is taken.

In order to confirm the diagnosis in this group of patients, also in individuals with failure in responding to the standard line of therapy for pyelonephritis, an urgent CT scan should be taken.[134]

The preliminary treatment is a medical management(MM) by providing basic resuscitation measures of oxygen, intravenous fluids, acid base balance correction and proper antibiotics along with good glycemic control. It is also necessary to sustain systolic blood pressure at above $100 \mathrm{mmHg}$ through fluid resuscitation or inotropic support if a need arises.

In case of observing deterioration in the clinical condition and the laboratory results, these patients should be looked after more vigorously as multi-organ support is possibly required.

The initial antibiotic therapy should be aimed at eliminating Gram-negative bacteria as the most common causative organisms. To fulfill this, Aminogycosides, a-lactamase inhibitors, 
cephalosporins and quinolones could be administered guided by the local hospital policy. For the initial stage of treatment, a combination of aminoglycoside with any of the other three groups can be used. The choice of antibiotics could be changed for the type and number of organisms along with their individual sensitivities accordingly once the culture report is ready.

Emergency nephrectomy and/or open surgical drainage along with antibiotic therapy was the accepted treatment of EPN until the late 1980s that had a mortality rate of up to $40-50 \%$ $[123,139]$.

As introduced by Hudson et al., fluoroscopy guided percutaneous drainage (PCD) has been an option for treating EPN. [140] In a number of case studies later, patients have been successfully treated with a significant reduction in mortality rates in case of an early PCD in combination with medical management $[129,132]$. PCD has also been found to be helpful in preserving the function of the affected kidney in about $70 \%$ of cases [127]. In patients who have been found to have localized areas of gas and in those with existing functioning renal tissue, early PCD should be performed.

Since more than one catheter can be used to drain all, hence, loculations, abscess or multiple abscesses are not contraindications for PCD [127, 141]. The first target of the PCD should be the abscess that is technically accessible easier and could significantly reduce the pressure on the viable renal tissue. As there is a better success rate if compared with ultrasonography, ideally the insertion of a pigtail drain of at least 14 Fr should be guided under CT [134].

Unless follow-up CT shows resolution of the EPN features, the drainage tubes should stay in place, and if needed, flushed with antibiotic solutions.

A gradual shift toward a nephron-sparing approach with early PCD has been noticed during the last decade with or without elective nephrectomy at a later stage. The various treatment strategies could be summarized as MM alone, early PCD plus MM, MM plus emergency nephrectomy, and PCD plus MM plus emergency nephrectomy [127] (Figure 2).

Chen et al. have recommended follow-up CT in 4 to 7 days as beneficial to look for noncommunicating air/fluid collections in patients with early PCD plus MM [141]. This could also be found helpful in planning a nephrectomy for non-responders to PCD plus medical management.

MM with PCD has found to be the most successful management method (30-100\%) in two meta-analysis of the management strategies which has also been linked with the lowest mortality rate at $13.5 \%$ ( $P$ 0.001) [127]. Nonetheless, subsequent nephrectomy could be required in a small proportion of patients managed with MM and PCD and the reported mortality stands at $6.6 \%$ that is significantly lower than medical management only approach $(50 \%)$, or emergency nephrectomy $(25 \%)$ alone (p_0.001) [127, 131].

MM alone or combined with PCD can lead to a good outcome in Class 1 and 2 EPN based on the Huang and Tseng classification. The survival rate with MM plus PCD is $85 \%$ in patients with fewer than two risk factors in Class 3 and 4 EPN, however, MM plus PCD was unsuccessful in $92 \%$ of cases in those patients with more than two risk factors. In comparison with the Class 1 and $2 \mathrm{EPN}$, the number of non-responders in this group who require nephrectomy is higher [130,132].

After PCD, the respective failure and mortality rates of $71 \%$ and $29 \%$ rate in Class $3 \mathrm{~A}$, and $30 \%$ and $19 \%$ in Class 3B have been described by Huang and Tseng [130].

A meta-analysis has revealed that in patients who underwent an early PCD, elective nephrectomy is required only in $13 \%$ of them [127]. These patients either do not respond 
well clinically to MM plus PCD, or on nuclear imaging they are found to have a nonfunctioning kidney.

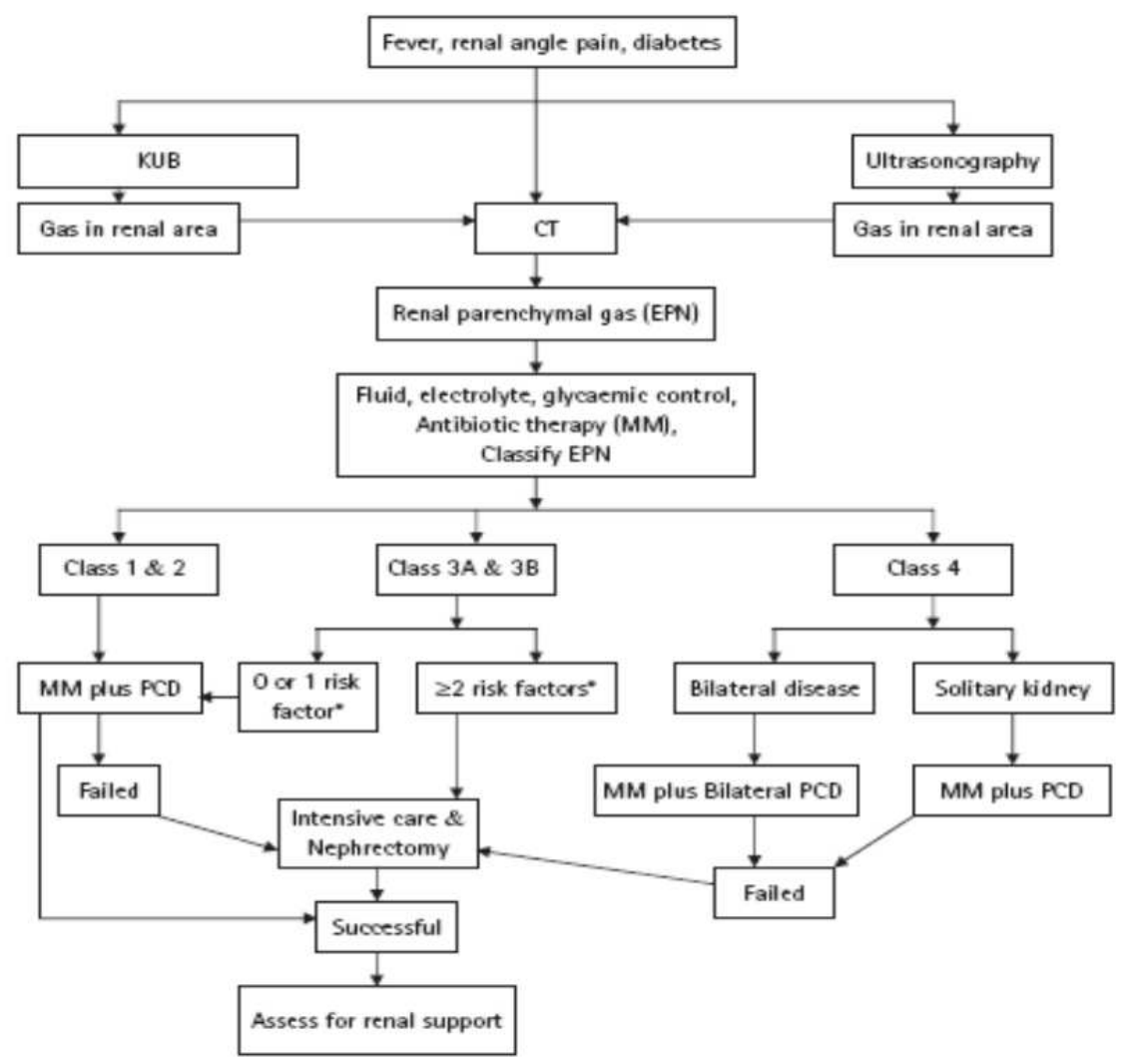

*Risk factors: diabetes, thrombocytopenia, acute renal failure, altered level of consciousness, shock.

Fig. 2. EPN Management algorithm that is based on clinico-radiological classification by Huang \& Tseng [130]. KUB, plain abdominal film of kidney, ureter and bladder.

In these patients, nephrectomy can be either simple, or radical, or laparoscopic [124, 142]. The mortality rate could be as low as $10 \%$ if simple nephrectomy can be carried out [124, 138]. Laparoscopic nephrectomy has been performed successfully in these patients with the advantage of a shortened recovery period and hospital stay [142].

Renal support measures in the form of dialysis might be required in patients with EPN that it seems the availability of renal support reduces the mortality rate as concluded in a recent study [132].

The best management strategy should be chosen based on an individualized case by case approach until prospective randomized studies come up with a definite conclusion. The degree and extent of parenchymal loss together with the coexisting renal disease determine the long-term outcome for renal function and the need for further support. 


\section{Xanthogranulomatous pyelonephritis}

\subsection{Introduction}

In medical literature, xanthogranulomatous pyelonephritis (XPN) is described as a rare, severe, chronic renal infection typically resulting in diffuse renal destruction. There is a unilateral involvement in most cases that ends in a nonfunctioning, enlarged kidney associated with obstructive uropathy as a result of nephrolithiasis [143]. The most common pathology that is attributed to the disease is the simultaneous obstruction of the ipsilateral renal unit, most commonly due to an underlying stone disease with concomitant urinary tract infection [143]. In 1916, Schlagenhaufer presented the first descriptions of the distinctive gross and macroscopic features of XPN; however, the term xanthogranulomatous pyelonephritis was introduced by Oberling in 1935 [144].

The characteristic of xanthogranulomatous pyelonephritis is the renal parenchyma destruction and its replacement by a chronic inflammatory infiltrate and lipid-laden macrophages called xanthoma cells [145] that in turn results in an enlarged kidney that is either poorly functional or non-functional.

Although the disease can be observed at any age, the majority of cases occur in middle-aged women. As it can affect the neonates, there is a possibility of prenatal origin as well [146]. XPN has been known to imitate virtually every other inflammatory disease of the kidney and on radiographic examination it is usually mistaken for renal cell carcinoma[147]. Moreover, because of the confusing microscopic similarities between xanthogranulomatous and clear cell adenocarcinoma of kidney on frozen section, it has ended in radical nephrectomy [145, 147, 148].

\subsection{Pathogenesis}

With regards to the pathogenesis, the primary factors involved in xanthogranulomatous pyelonephritis are nephrolithiasis, obstruction, and infection [149]. In up to $83 \%$ of the patients in various series, they have been found to have nephrolithiasis that staghorn type has comprised approximately one third to half of the renal stones [147, 150-152]. To a lower extent, there have also been reports of urinary tract obstruction as a result of UPJ obstruction, severe VUR and tumors (e.g. renal cell carcinoma, ureteral carcinoma, bladder carcinoma)[150, 153]. Also there is a greater risk of developing the disease in diabetics [154].

There has been a clinical and experimental postulation that primary obstruction with or without subsequent bacterial infection can lead to the tissue damage with the release of lipid material initiating the XPN. The lipid material is collected by macrophages. Then, these macrophages (xanthoma cells) are spread in sheets around parenchymal abscesses and calyces and are intermixed with lymphocytes, giant cells, and plasma cells. As spontaneous bacteriemia has been reported rarely, the bacteria seem to be of low virulence $[143,155]$.

Venous occlusion and hemorrhage, abnormal lipid metabolism, lymphatic blockage, failure of antimicrobial therapy in UTI, altered immunologic competence, and renal ischemia are the other factors possibly interrelated [156, 157].

The fact that XPN is treated successfully by nephrectomy, also the lack of other evidence for the systemic immune deficiency, has led to the assumption that immunological defect is unlikely. The reported malnutrition in these patients seems to be attributable to the effect of the XPN rather than its cause. Nonetheless, the cycle of events in the XPN pathogenesis is unclear [158]. 
In the studies so far, no single factor has found to be instrumental in the pathogenesis of this disease. Instead, insufficient host acute inflammatory response within an obstructed, ischemic, or necrotic kidney seems to be the culprit.

\subsection{Pathology}

Grossly, kidney involvement in xanthogranulomatous pyelonephritis could be diffuse $(80 \%)$, or segmental as well as surrounding tissues.

The involved kidney is usually described as enlarged, with normal outline and the indication of nephrolithiasis, peripelvic fibrosis and dilated calyces filled with purulent material; however, the pelvis that is surrounded by fibrosis usually prevents pelvic dilation. Papillary necrosis leads to destruction of the papillae [143].

Typically, orange-yellow nodules of inflamed parenchymal tissue near the areas of tissue necrosis suppuration could be observed. Besides small localized abscess is a common finding. The renal cortex is thin and the xanthogranulomatous tissue usually replaces it. The renal capsule often thickens, and the inflammatory process expansion into the perinephric or paranephric space is common $[143,149,156]$.

In microscopic examination, yellowish nodules that line the calyces and surround the parenchymal abscesses with dark sheets of lipid-laden macrophages or xanthoma cells (foamy histiocytes with small, dark nuclei and clear cytoplasm) could be noted (Figure 3). There is a mixture of the macrophages with a variety of inflammatory cells such as lymphocytes, plasma cells, neutrophils, and multinucleated giant cells. This seems necessary to mention that the presence of xanthogranulomatous cells is unspecific to xanthogranulomatous pyelonephritis and they may be found anywhere inflammation or obstruction exits [143, 156].

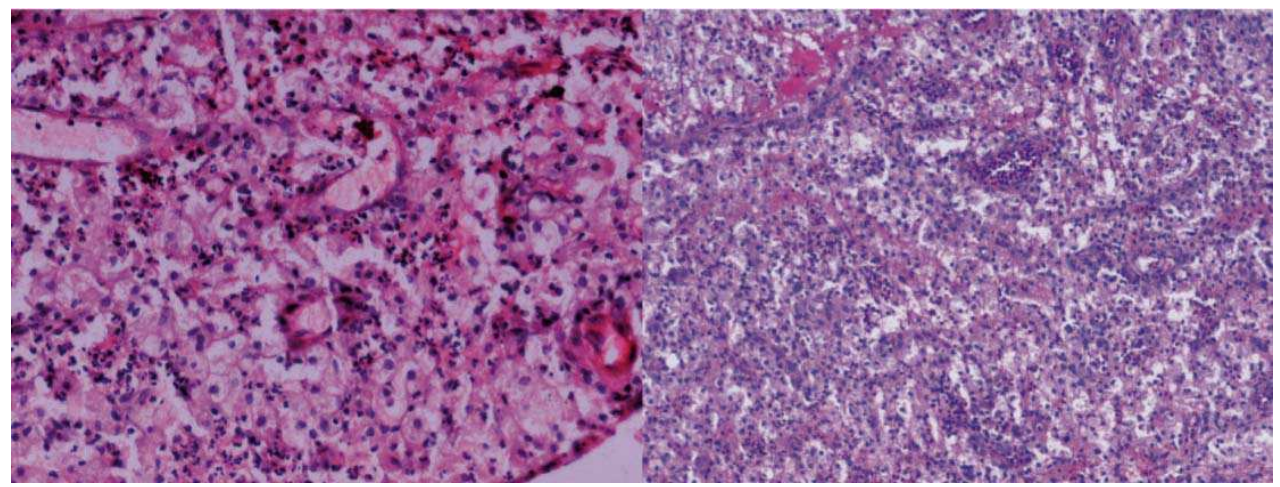

Fig. 3. Xanthogranulomatous pyelonephritis. Prominent foamy histocyes admixed with mononuclear cells. ( Courtesy of Simforoosh N., Sharifiaghdas F., Parvin M.,et al. The book "Urology Cases in Practice". Labbafinejad Medical Center, Tehran, Iran.)

\subsection{Clinical presentation}

In patients with UTIs and a unilateral enlarged nonfunctioning or poorly functioning kidney with a stone or a mass lesion indistinguishable from malignant tumor, xanthogranulomatous pyelonephritis should be considered in the differential diagnosis. Since it has been termed "the great imitator" indicates the difficulty to characterize its 
clinical and radiologic features. As a result, in most cases the precise diagnosis is made at the time of histopathology after nephrectomy.

The disease presentation is nonspecific and its clinical demonstration varies markedly. The usual findings in most patients include flank pain, fever, and constitutional symptoms of fatigue, malaise, weight loss, and anorexia. Among those, a tender flank mass is the most common physical finding.

In up to $50 \%$ of patients, there are abnormal liver function tests with occasional hepatomegaly.

XGP inflammation could be extended into the perirenal or pararenal space, lymph nodes, ipsilateral Psoas muscle, colon, spleen, diaphragm, abdominal wall, and skin. This process is similar in pediatric patients and adults with similar clinical and pathologic findings. The classic triad is unilateral renal enlargement with little or no function and a large calculus in the renal pelvis without pelvic dilation in fifty to eighty percent of patients. A positive medical history for UTIs and urologic instrumentation could often be extracted. [152, 154, $155,158,159]$.

Although xanthogranulomatous pyelonephritis with its unknown etiology can occur at any age; however, the peak age for its incidence is in the fifth to the seventh decade that predominantly affects women with no preference of involving either kidney [158].

\subsection{Paraclinic findings}

In the literature review for the xanthogranulomatous pyelonephritis it can be realized that Proteus is the most common organism involved followed by E. coli [151, 158].The stone formation and subsequent chronic obstruction and irritation could be attributable to Proteus organisms [147]. Polymicrobial infections have found to be the responsible organisms in $33 \%$ of a series of 36 cases that included some anaerobics.

No microbial growth could be detected in the urine of one-third of the patients. It seems that the reason is either the preventive effect of the urinary tract obstruction not allowing the contaminated urine to reach the bladder, or it is because of the antibiotic treatment prior to the patient's admission [151]. In some cases, only the cultures of the tissue obtained during the operation could reveal the organism. The common findings in urinalysis are pyuria and proteinuria; nonetheless, urine culture is sterile in $35 \%$ of patients. Blood tests are usually indicative of anemia and leukocytosis that hepatic dysfunction could be found in as high as $50 \%$ of the patients [159]. Azotemia or serious renal failure is uncommon due to the almost always unilateral involvement in xanthogranulomatous pyelonephritis [149].

In sonography, a global enlargement of the kidney is usually found. Instead of the normal renal parenchyma, many hypoechoic fluid-filled masses are detected that are debris-filled dilated calyces or foci of parenchymal destruction. In focal involvement, a solid mass is present in the involved segment of the kidney with an associated calculus in the collecting system or ureter. As to the differential diagnosis, renal cell carcinoma and other solid renal lesions must be considered [160].

A renal mass due to a localized renal enlargement could be presented. Less common findings in excretory urography are delayed function and possibly a massive hydronephrosis. Although smaller calcifications within the mass are not uncommon, however, they are not very specific.

The point of obstruction could be shown by retrograde pyelography that it also reveals the dilation of the renal pelvis and calyces. In contrast studies, extensive parenchymal damage 
could be demonstrated as an ulcerated pyelocalyceal system with multiple irregular filling defects.

The most valuable radiologic means in evaluating patients with xanthogranulomatous pyelonephritis is probably CT scanning (Figure 4). By using this radiologic technique, an enlarged nonfunctioning kidney with decreased contrast enhancement, dilated calyces, and the evidence of obstruction often by a renal stone could be demonstrated [161, 162]. At times, a large reniform mass with the renal pelvis closely encircling a central calcification, but without pelvic dilatation, could be demonstrated [160,163]. In the scans, multiple waterdensity masses that are representative of dilated calyces and abscess cavities filled with varied amounts of pus and debris could be observed instead of normal renal parenchyma. On enhanced scans, however, the abundant vascularity within the granulation tissue could make the walls of these cavities demonstrate a prominent blush. In contrast to the tumors and other inflammatory lesions, the cavities themselves, do not enhance in the scans.

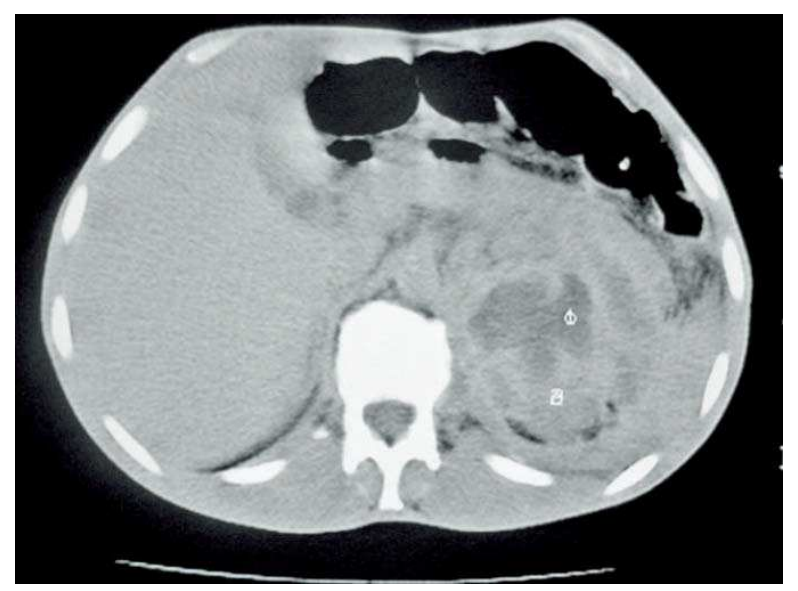

Fig. 4. CT scan :a multifocal mass in left kidney(transverse view). ( Courtesy of Simforoosh N., Sharifiaghdas F., Parvin M.,et al. The book "Urology Cases in Practice". Labbafinejad Medical Center, Tehran, Iran.)

In properly evaluating the involvements of the perirenal and pararenal tissues, CT scan is very helpful that could reveal extension of the inflammatory process into structures nearby, or abdominal wall $[154,161]$.

In order to confirm and quantify the differential lack of function in the involved kidney, 99mTc-DMSA radionuclide renal scanning is exploited [149].

MRI has not excelled CT in assessing renal inflammation yet, however, it has the advantage of outlining extra renal extension of inflammation. On T1 and T2-weighted images, lesions of xanthogranulomatous pyelonephritis could emerge as cystic foci of intermediate intensity and hyper intensity signal, respectively [164].

Xanthogranulomatous pyelonephritis and renal cell carcinoma cannot usually be differentiated in the radiologic studies despite the distinctive radiologic signs. The decisive diagnosis is usually made pathologically, mostly after nephrectomy. In the last decade, however, a combination of increasingly sensitive radiologic investigations and suspicious clinical signs has made the preoperative diagnosis possible. 


\subsection{Differential diagnosis}

In segmental xanthogranulomatous pyelonephritis with no calculus, the diagnosis may be difficult. In a small contracted kidney, the radiographic findings are nonspecific and nondiagnostic for XPN [161, 163].

The usual differential diagnoses for xanthogranulomatous pyelonephritis are Wilms tumor, renal cell carcinoma, renal abscess, infected renal cystic disease, tuberculosis, malakoplakia, and transitional renal cell carcinoma. There have also been the reports of cases associated with renal carcinoma [148, 155].

Differentiation between xanthogranulomatous pyelonephritis presented with massive pelvic dilation and pyonephrosis is not possible. In renal parenchymal malacoplakia, there may be renal enlargement and multiple inflammatory masses instead of the normal renal parenchyma, however, calculi are usually absent. Renal lymphoma could be presented by multiple hypoechoic masses in the kidney enclosing the contracted, non-dilated pelvis. Nevertheless, the clinical signs for lymphoma are clear and calculi are absent and the renal involvement is usually bilateral [160].

\subsection{Management}

The correct diagnosis is the first issue to tackle in the correct treatment of xanthogranulomatous pyelonephritis. XPN used to be diagnosed mostly postoperatively in the past [147]. With today's accurate modern CT technology, diagnosis nears 90\% preoperatively $[152,158]$.

To stabilize the patient preoperatively, antimicrobial therapy is necessary that the renal function could be occasionally restored by eradicating the infection through long-term antimicrobial therapy[165].

In a study by Tasi et al., an adult case was reported who had bilateral diffuse XPN with no fever and was successfully managed by supportive care without renal replacement therapy. The subsequent eighteen-month follow-up was proven to be uneventful with relatively stable renal function (serum creatinine $10.6 \mathrm{mg} / \mathrm{dl}$ ). Therefore, it seems fever could be used as an indicator for nephrectomy [166]. Nonetheless due to the limited reported cases, the significance of pyrexia should be investigated further for its importance to be fully recognized.

If the renal involvement is either diffuse or indistinguishable from a renal tumor preoperatively, nephrectomy is carried out. Nonetheless, for the localized xanthogranulomatous pyelonephritis, diagnosed preoperatively or at exploration, partial nephrectomy is preferred [147, 157].

To make the diagnosis solely on the basis of frozen section could be difficult as the lipidladen macrophages associated with xanthogranulomatous pyelonephritis are very similar to clear cell adenocarcinoma. There also seems to be relations between the cells in xanthogranulomatous pyelonephritis and renal cell carcinoma, papillary transitional cell carcinoma of the pelvis or bladder, and infiltrating squamous cell carcinoma of the pelvis $[148,157]$. As a result, nephrectomy should be performed if malignant renal tumor cannot be ruled out. In case of an encounter with enlarged lymph nodes, the nodes should be dissected to exclude coexisting renal cell carcinoma[148].

If there is a diffuse and extensive disease that extends to the retroperitoneum, nephrectomy accompanied by the removal of the perinephric fat and the dissection of granulomatous tissue from the diaphragm, great vessels, and bowel may be required. 
If nephrectomy is not performed and incision and drainage is carried out instead, the patient may continue suffering from a prolonged incapacitating illness that could advance toward cutaneous fistula and in such cases an even more difficult nephrectomy will then be necessary [147].

Laparoscopic nephrectomy has been concluded as a reasonable approach to the treatment of xanthogranulomatous pyelonephritis in some literature reviews, but the fact is that most $\mathrm{XPN}$ cases were managed through open surgery and the conversion rate was high in those few cases that laparoscopic approach had been tried [159, 167].

\section{Malacoplakia}

\subsection{Introduction}

The Greek word "Malacoplakia" literally means soft plaque and the term is used for any unusual inflammatory disease that was originally described to affect the bladder, however, it has been found later that it could affect the genitourinary and gastrointestinal tracts, skin, lungs, bones, and mesenteric lymph nodes. Originally, this chronic inflammatory lesion was described by Michaelis and Gutmann in 1902. In 1903, it was characterized by von Hansemann as soft, yellow-brown plaques with large polygonal shaped macrophages and foamy eosinophilic cytoplasm (von Hansemann cells) that the pathognomonic PAS-positive granules are called Michaelis-Gutmann bodies [168]

Malacoplakia does not have exact known pathogenesis; however, it probably results from abnormal macrophage function against a bacterial infection, mostly E. coli.

\subsection{Pathogenesis}

Although the true pathogenesis is unknown, but there are several popular theories available. Of some 93 patients who had cultures of urine, diseased tissue, or blood, $89.4 \%$ were found to have coliform infections [168]. Of the total number of patients in this review, some $40 \%$ of the patients had an immunodeficiency syndrome, autoimmune disease, carcinoma, or another systemic disorder. In malacoplakia, this association of coliform infections and patients' compromised health status is well recognized.

The distinguishable Michaelis-Gutmann bodies are believed to originate from the phagolysosomes containing incompletely destroyed bacteria with abnormal deposition of calcium and iron [168]. As many authors agree there is a decreased intra cellular cGMP/cAMP ratio that seems to diminish capacity of macrophages for bacterial lysis. Hence, in Malacoplakia the assumption exists that the underlying cellular defect is the impaired intracellular killing of bacteria $[169,170]$. The most frequent bacteria associated with malacoplakia are coliforms that in $75 \%$ of cases is E. coli [169].

\subsection{Pathology}

To diagnose the disease, biopsy should be carried out that the lesion has the characteristic large histiocytes, known as von Hansemann cells, and pathognomonic small basophilic, extracytoplasmic, or intracytoplasmic calculospherules called Michaelis-Gutmann bodies. Electron microscopy has been able to demonstrate the intact coliform bacteria and bacterial fragments within phagolysosomes of the foamy-appearing malacoplakic histiocytes [168]. It has been emphasized that Michaelis-Gutmann bodies though pathognomonic for the disease, may not be observed in early malacoplakia; hence, they are not necessary for the diagnosis $[168,171]$. 
Large amounts of immunoreactive $a_{1}$-antitrypsin have been detected in macrophages in malacoplakia involving the kidney and bladder [172]. In other pathologic processes that macrophages closely look alike the ones in malacoplakia, but without Michaelis-Gutmann bodies, they do not contain $a_{1}$-antitrypsin that is with the exception for a few macrophages in tuberculosis and xanthogranulomatous pyelonephritis. In malacoplakia, hence, $\mathrm{a}_{1^{-}}$ antitrypsin immunohistochemical staining could be a useful test for an early and accurate differential diagnosis.

\subsection{Clinical presentation}

The majority of patients are females who are over the age of 50 with a recurrent urinary tract infection history. For the malacoplakia in the urinary tract, the female to male ratio is $4: 1$; however, this ratio does not stand for other body tissues [168, 169]. The affected patients who are mostly debilitated, are immunosuppressed, with other chronic diseases and they are similar to those patients on long-term steroid administration and individuals with acquired immunodeficiency syndrome, lymphoma, and diabetes mellitus [168].

Malacoplakia could appear through various clinical presentations that is appropriate to the location of the disease-associated plaques and can involve any portion of the urinary tract, nonetheless, the bladder is the most commonly involved site and it is followed by the renal parenchyma, ureters, and renal pelvis $[168,169]$.

The symptoms for the bladder malacoplakia that is more common than the other types of urinary tract involvement are bladder irritability and hematuria. In cystoscopy, mucosal plaques or nodules could be detected. With the progress of these lesions, they may become fungating, firm, sessile masses that result in filling defects of the bladder, ureter, or pelvis on excretory urograms. The disease process may cause distal ureter to be strictured or stenotic with subsequent renal obstruction or nonfunction [173].

In malacoplakia, the common renal parenchymal disease may be presented with flank pain or tenderness, palpable mass, pyuria, hematuria, and fever [173] accompanied by the history of urinary tract infections. Due to the usual enlargement of the affected kidney, it is commonly misdiagnosed as renal abscesses or malignant growths, particularly if there is concomitant lung involvement that can mimic metastatic disease [174]. In rare cases, malacoplakia has been reported as bilateral hydronephrosis and ureteral involvement [173, 175]. It can also cause renal vein thrombosis, inferior vena cava thrombosis, or progressive renal failure. Malacoplakia should be considered in the differential diagnosis of acute renal failure if it directly involves the renal parenchyma, also in those rare cases of bilateral renal disease that the end-stage renal failure has been resulted [173, 176].

The renal malacoplakia may extend beyond the kidney and it may also be potentially fatal due to post-infectious glomerulonephritis secondary to bacterial presence in the renal parenchyma, and unlike bladder involvements, is a progressive and destructive parenchymal disease $[177,178]$.

With the advancement of the medical science, renal parenchymal disease is no longer considered as a frequently fatal disease in the new millennium; however, the morbidity rate still remains high and progress toward renal failure will ensue in a considerable number of patients with time [176].

\subsection{Paraclinic findings}

Urine cytology: It could possibly reveal the presence of cells with Michaelis- Gutmann bodies in the urine sample tested [179]. 
Depending on the degree of internal necrosis, ultrasonography and CT may demonstrate a solid or cystic structure. Ultrasonography, CT, and arteriography are helpful means to establish the multifocal nature.

The most common sonographic finding in renal parenchymal malacoplakia is diffuse enlargement of the affected kidneys, and to a lower extent, hypoechoic lesions, distortion of parenchymal echoes, and increased echogenicity of the parenchyma could be observed too $[180,181]$.

The most common CT findings include nephromegaly and parenchymal inhomogeneity. The density of the foci of malacoplakia is less than the surrounding enhanced parenchyma. Nevertheless, there have been images available mimicking malignant renal infiltration presenting by masses with increased focal uptake, heterogenecity of focal necrosis, abscesses and multiple retroperitoneal lymph node of significant size with hypodense necrotic center $[179,182]$. CT has also the best capability to demonstrate the extension beyond the kidney occurring either in multifocal or uniform malacoplakia [182].

The typical presentation of the multifocal malacoplakia on excretory urography is enlarged kidneys with multiple filling defects and it is on the contrary to the unifocal lesion that appears as a non-calcified mass indistinguishable from other inflammatory or neoplastic lesions. Moreover, renal calcification, lithiasis, and hydronephrosis do not exist [183].

In a typical arteriography, a hypovascular mass without peripheral neovascularity could be observed [183].

\subsection{Differential diagnosis}

Histopathologic analysis could establish the diagnosis; yet the diagnostic value of the cytologic analysis of fine-needle aspirates has also been demonstrated. Since malacoplakia has no characteristic clinical or radiologic sign, thus, biopsy is crucial both to confirm the diagnosis and to help exclude other possible pathologies [184].

In case of observing one or more renal masses, malacoplakia should be suspected, particularly in females with recurrent UTIs with E. coli, altered immune response syndromes, or cystoscopic evidence of malacoplakia or filling defects in the collecting system. In a renal transplant patient with these radiographic findings and persistent UTI who has received appropriate antimicrobial therapy, malacoplakia should also be suspected. The differential diagnoses to consider are renal cystic disease, neoplasia, and renal inflammatory disease [184]. To exclude cystic disease in general, careful sonographic and CT evaluations could be carried out. In the course of the disease, late renal involvement with metastatic disease or lymphomas usually occurs that is well documented. Most often, multifocal renal cell carcinoma is seen in the context of von Hippel-Lindau disease together with its other clinical manifestations. Similar to malacoplakia, signs and symptoms of UTI are usually available in the patients with xanthogranulomatous pyelonephritis and the involved kidney is enlarged; however, renal calculi and obstruction are common. Multiple renal abscesses are often the result of hematogenous dissemination originated by cardiac disease.

\subsection{Management}

To stabilize the disease process and to manage malacoplakia, the control of the UTIs should be the target of the treatment [168].

An antibiotic with an excellent cell membrane penetration is the cornerstone of treatment that fluoroquinolones are effective in up to $80-90 \%$ of cases and since their debut in the 
early 90 's, they have been the greatest support in the literature to manage the disease [176, 185]. They have been the first choice of treatment due to the easy passage through the macrophage and histiocyte cell wall providing high concentrations there [179, 186].

Despite the use of various long-term antimicrobial agents such as many antituberculosis agents, however, the sulfonamides, rifampin, doxycycline, and TMP are found to be particularly useful owing to their intracellular bactericidal activity $[179,185]$.

In the patients that receive immunosuppressive therapy for any reason, the suspension of their medications is advisable during the treatment period.

As phagocytic dysfunction is supposedly the reason behind the malacoplakia, the use of ascorbic acid (Vitamin C) and cholinergic agents such as bethanechol in conjunction with antimicrobial therapy have been reported with good results in the restoration of phagocytic function [168, 179]. It is believed that the aforesaid agents work through increasing intracellular cyclic guanosine monophosphate levels (cGMP) that its biologic defect seemingly leads to macrophage dysfunction and its availability restores lysosomal function that in turn enhances phagocytosis.

If the disease progresses in spite of antimicrobial treatment, surgical intervention could be indicated that for the treatment of symptomatic unilateral renal lesions, nephrectomy is usually performed. As to the often very aggressive nature of the retroperitoneal involvement, it could be fatal $[176,179]$.

Prognosis seems appropriate to the extent of the disease in the long-term. In bilateral parenchymal renal malacoplakia or in the transplanted kidney the survival is usually limited to 6 months $[179,186]$. On the opposite, the long-term survival after nephrectomy in the unilateral disease is good that in a literature review in 2003, the survival rate was found to be over $90 \%$ in such patients. Nonetheless due to the possible long-term relapse, these patients must always undergo close evaluation periodically [176].

\section{References}

[1] Best, C.D., et al., Clinical and radiological findings in patients with gas forming renal abscess treated conservatively. J Urol, 1999. 162(4): p. 1273-6.

[2] Rinder, M.R., Renal abscess: an illustrative case and review of the literature. Md Med J, 1996. 45(10): p. 839-43.

[3] Cheng, C.H., et al., Renal abscess in children: a 10-year clinical and radiologic experience in a tertiary medical center. Pediatr Infect Dis J, 2008. 27(11): p. 1025-7.

[4] D'Cruz, S., et al., Isolation of Salmonella paratyphi A from renal abscess. Indian J Pathol Microbiol, 2009. 52(1): p. 117-9.

[5] Dravid, M. and B.N. Joshi, Renal abscess due to Salmonella typhimurium. Indian J Pediatr, 1990. 57(4): p. 586-8.

[6] Valbuena Alvarez, R., et al., [Acute systemic nocardiosis. Renal abscess]. Arch Esp Urol, 1996. 49(5): p. 529-31.

[7] Osanai, S., et al., Renal abscess with Morganella morganii complicating leukemoid reaction. Intern Med, 2008. 47(1): p. 51-5.

[8] Woods, C.R. and M.S. Edwards, Renal abscess caused by group B Streptococcus. Clin Infect Dis, 1994. 18(4): p. 662-3.

[9] Lin, M.F., et al., Serratia marcescens renal abscess with endophthalmitis: a case report. J Microbiol Immunol Infect, 1998. 31(4): p. 245-8. 
[10] Metta, H., et al., Renal abscess due to Aspergillus fumigatus as the only sign of disseminated aspergillosis in a patient with AIDS. Rev Iberoam Micol, 2010. 27(3): p. 136-9.

[11] Colebunders, R., et al., Renal abscess due to Mycobacterium avium complex in a human immunodeficiency virus-positive patient. Int J Infect Dis, 2002. 6(3): p. 238-9.

[12] Chen, K.J., et al., Endogenous Klebsiella pneumoniae endophthalmitis with renal abscess: Report of two cases. Int J Infect Dis, 2010. 14(5): p. e429-32.

[13] Olson, E.S., et al., A case report of renal abscess caused by Salmonella virchow phage type 1 associated with a papillary renal cell carcinoma. J Infect, 1999. 38(1): p. 56-7.

[14] Shoji, S., et al., [Renal infarction with renal abscess onset due to infective endocarditis: a case report]. Hinyokika Kiyo, 2008. 54(3): p. 221-3.

[15] Chang, S.W., et al., Klebsiella pneumoniae renal abscess. Zhonghua Yi Xue Za Zhi (Taipei), 2000. 63(10): p. 721-8.

[16] Shimizu, M., et al., Evolution of acute focal bacterial nephritis into a renal abscess. Pediatr Nephrol, 2005. 20(1): p. 93-5.

[17] Steele, B.T., C. Petrou, and J. de Maria, Renal abscess in children. Urology, 1990. 36(4): p. 325-8.

[18] Sugao, H., H. Takiuchi, and T. Sakurai, Acute focal bacterial nephritis and renal abscess associated with vesicoureteral reflux. Report of a case. Urol Int, 1988. 43(4): p. 253-6.

[19] Wang, Y.T., et al., Renal abscess in children: a clinical retrospective study. Acta Paediatr Taiwan, 2003. 44(4): p. 197-201.

[20] Pieretti, R.V., R. Pieretti-Vanmarcke, and A. Pieretti, Renal abscess in previously healthy girl. Urology, 2009. 73(2): p. 297-8.

[21] Ybarra, M.E., L. D'Ambrosio, and A. Fioravanti, [Renal abscess]. Arch Argent Pediatr, 2011. 109(2): p. 173-174.

[22] Constantine, S. and J. Kaye, Metastatic renal abscess mimicking Wilms' tumour. Pediatr Radiol, 2004. 34(11): p. 924-6.

[23] Sule, A.Z., Undiagnosed renal abscess presenting as acute bacterial peritonitis: case report. East Afr Med J, 2001. 78(9): p. 500-1.

[24] Deryckere, A., et al., [Endogenous Klebsiella pneumoniae endophthalmitis secondary to a renal abscess: a case report]. J Fr Ophtalmol, 2009. 32(4): p. 280-3.

[25] Gillitzer, R., et al., Transitional cell carcinoma of the renal pelvis presenting as a renal abscess. Urology, 2002. 60(1): p. 165.

[26] Perimenis, P., Pyonephrosis and renal abscess associated with kidney tumours. Br J Urol, 1991. 68(5): p. 463-5.

[27] Kawashima, A., C.M. Sandler, and S.M. Goldman, Imaging in acute renal infection. BJU Int, 2000. 86 Suppl 1: p. 70-9.

[28] Hoddick, W., et al., CT and sonography of severe renal and perirenal infections. AJR Am J Roentgenol, 1983. 140(3): p. 517-20.

[29] Soulen, M.C., E.K. Fishman, and S.M. Goldman, Sequelae of acute renal infections: CT evaluation. Radiology, 1989. 173(2): p. 423-6.

[30] Kumar, R., et al., Indium-111 leukocyte scanning. False-negative study in a renal abscess. Clin Nucl Med, 1986. 11(4): p. 274-5.

[31] Siegel, J.F., A. Smith, and R. Moldwin, Minimally invasive treatment of renal abscess. J Urol, 1996. 155(1): p. 52-5.

[32] Hung, C.H., et al., Immediate percutaneous drainage compared with surgical drainage of renal abscess. Int Urol Nephrol, 2007. 39(1): p. 51-5. 
[33] Gardiner, R.A., R.A. Gwynne, and S.A. Roberts, Perinephric abscess. BJU Int, 2011. 107 Suppl 3: p. 20-3.

[34] Ko, M.C., et al., Incidence of renal and perinephric abscess in diabetic patients: a population-based national study. Epidemiol Infect, 2011. 139(2): p. 229-35.

[35] Hutchison, F.N. and G.A. Kaysen, Perinephric abscess: the missed diagnosis. Med Clin North Am, 1988. 72(5): p. 993-1014.

[36] Truesdale, B.H., S.N. Rous, and R.P. Nelson, Perinephric abscess: a review of 26 cases. J Urol, 1977. 118(6): p. 910-1.

[37] Al-Soub, H., et al., Shigella flexneri perinephric abscess and bacteremia. Ann Saudi Med, 2005. 25(5): p. 419-21.

[38] Vaidyanathan, S., et al., Superinfection of perinephric abscess by Stenotrophomonas maltophilia in a tetraplegic patient. Spinal Cord, 2005. 43(6): p. 394-5.

[39] D'Cruz, S., et al., Isolated nocardial subcapsular and perinephric abscess. Indian J Pathol Microbiol, 2004. 47(1): p. 24-6.

[40] Baumgardner, D.J., Perinephric abscess caused by group B streptococcus. Am Fam Physician, 2004. 69(12): p. 2764, 2766.

[41] Khemakhem, B., et al., [Candida glabrata perinephric abscess. A case report]. Ann Med Interne (Paris), 2001. 152(2): p. 134-6.

[42] Rajesh, G.D., et al., Perinephric abscess due to Aspergillus fumigatus. Indian J Pediatr, 2000. 67(7): p. 545-6.

[43] Gomber, S., et al., Perinephric abscess (presenting as abdominal pain) due to Listeria monocytogenes. Ann Trop Paediatr, 1998. 18(1): p. 61-2.

[44] Chitnavis, V. and C.R. Magnussen, Perinephric abscess due to a coagulase-negative Staphylococcus: case report and review of the literature. J Urol, 1993. 149(6): p. 1530-1.

[45] Rigg, K.M. and J.R. Sainsbury, Salmonella perinephric abscess. Br J Hosp Med, 1986. 36(4): p. 284-5.

[46] Khauli, R.B., S. Kalash, and J.D. Young, Jr., Torulopsis glabrata perinephric abscess. J Urol, 1983. 130(5): p. 968-70.

[47] Thompson, W.C. and J.W. Brock, 3rd, Torulopsis glabrata perinephric abscess: a case report. J Urol, 1983. 130(3): p. 529-30.

[48] Wunderlich, H.F., et al., Bacteroides fragilis perinephric abscess. J Urol, 1980. 123(4): p. 601-2.

[49] Suriyanon, V., K.E. Nelson, and V. Choomsai na Ayudhya, Trichomonas vaginalis in a perinephric abscess. A case report. Am J Trop Med Hyg, 1975. 24(5): p. 776-80.

[50] Camara, B., et al., Perihepatitis and perinephric abscess due to Mycoplasma hominis in a kidney transplant patient. Exp Clin Transplant, 2007. 5(2): p. 708-9.

[51] Santoro-Lopes, G., M. Halpern, and R.T. Goncalves, Perinephric abscess caused by Streptococcus agalactiae after renal transplantation. J Infect, 2005. 51(3): p. e145-7.

[52] Shohaib, S., Nocardial psoas and perinephric abscess in a renal transplant treated by surgery and antibiotics. Nephrol Dial Transplant, 1994. 9(8): p. 1209-10.

[53] Finkelhor, R.S., et al., Gardnerella vaginalis perinephric abscess in a transplanted kidney. N Engl J Med, 1981. 304(14): p. 846.

[54] Edelstein, H.E., R.E. McCabe, and E. Lieberman, Perinephric abscess in renal transplant recipients: report of seven cases and review. Rev Infect Dis, 1989. 11(4): p. 569-77.

[55] Maldonado-Alcaraz, E., et al., [Perinephric abscess: associated factors and mortality]. Arch Esp Urol, 2008. 61(1): p. 7-12. 
[56] Harrow, B.R., Spontaneous urinary extravasation associated with renal colic causing a perinephric abscess. Am J Roentgenol Radium Ther Nucl Med, 1966. 98(1): p. 47-53.

[57] Feldman, M.A., R.E. Cotton, and W.M. Gray, Carcinoma of the colon presenting as left perinephric abscess. Br J Surg, 1968. 55(1): p. 21-6.

[58] Chintapalli, K., et al., Perinephric abscess with renal cell carcinoma. Urol Radiol, 1981. 3(2): p. 113-5.

[59] Karamalegos, A.Z., A.C. Diokno, and D.F. Moylan, Formation of perinephric abscess following extracorporeal shock-wave lithotripsy. Urology, 1989. 34(5): p. 277-80.

[60] Kochakarn, W. and K. Ratana-Olarn, Late perinephric abscess formation after extracorporeal shock wave lithotripsy. Br J Urol, 1991. 68(3): p. 323-4.

[61] Pautler, S.E., J.F. Vallely, and J.D. Denstedt, Perinephric abscess following extracorporeal shockwave lithotripsy. Can J Urol, 1998. 5(4): p. 623-626.

[62] Reese, J.H., R.U. Anderson, and G. Friedland, Splenic abscess arising by direct extension from a perinephric abscess. Urol Radiol, 1990. 12(2): p. 91-3.

[63] Reiber, K. and I. Leventhal, Splenic abscess as complication of perinephric abscess. Urology, 1987. 30(3): p. 269-71.

[64] Kao, C.T., et al., Right perinephric abscess: a rare presentation of ruptured retrocecal appendicitis. Pediatr Nephrol, 2002. 17(3): p. 177-80.

[65] Wani, N.A., et al., Perinephric abscess caused by ruptured retrocecal appendix: MDCT demonstration. Urol Ann, 2010. 2(1): p. 29-31.

[66] High, K.P. and V.J. Quagliarello, Yeast perinephric abscess: report of a case and review. Clin Infect Dis, 1992. 15(1): p. 128-33.

[67] McLellan, R.A., M.A. Fischer, and P. Belitsky, Perinephric abscess presenting as chronic diarrhea. Can J Urol, 2000. 7(2): p. 983-5.

[68] Khan, A., M.Z. Hotiana, and S. Khan, Perinephric abscess presenting as acute peritonitis. Trop Doct, 1993. 23(1): p. 32.

[69] Runyon, B.A., Bacterial peritonitis secondary to a perinephric abscess. Case report and differentiation from spontaneous bacterial peritonitis. Am J Med, 1986. 80(5): p. 997-8.

[70] Curran, A.J., et al., Perinephric abscess as a presentation of pancreatitis. Br J Urol, 1993. 71(1): p. 97-8.

[71] Teelucksingh, S., et al., Perinephric abscess mimicking fulminant hepatic failure. West Indian Med J, 1994. 43(2): p. 66-7.

[72] Tsukagoshi, D., et al., Perinephric abscess secondary to a staghorn calculus presenting as a subcutaneous abscess. CJEM, 2006. 8(4): p. 285-8.

[73] Hampel, N., T.A. Sidor, and L. Persky, Nephrobronchial fistula. Complication of perinephric abscess secondary to ureteral obstruction and pyonephrosis. Urology, 1980. 16(6): p. 608-10.

[74] Stojadinovic, M., S. Micic, and D. Milovanovic, Ultrasonographic and computed tomography findings in renal suppurations: performance indicators and risks for diagnostic failure. Urol Int, 2008. 80(4): p. 389-97.

[75] Sweet, R. and W.F. Keane, Perinephric abscess in patients with polycystic kidney disease undergoing chronic hemodialysis. Nephron, 1979. 23(5): p. 237-40.

[76] Bickel, A., I. Waxman, and A. Eitan, Laparoscopic treatment of a perinephric abscess. Surg Endosc, 1995. 9(4): p. 437-8.

[77] Tamura, K., et al., Successful treatment for perinephric abscess with recombinant human granulocyte colony-stimulating factor following nephrectomy in a patient of myelodysplastic syndrome: a case report. Biotherapy, 1990. 2(3): p. 223-6. 
[78] Brook, I., Urinary tract and genito-urinary suppurative infections due to anaerobic bacteria. Int J Urol, 2004. 11(3): p. 133-41.

[79] Chijioke, A., Current concepts on pathogenesis of renal tuberculosis. West Afr J Med, 2001. 20(2): p. 107-10.

[80] Sharma, S., A. Mohta, and P. Sharma, Neonatal pyonephrosis--a case report. Int Urol Nephrol, 2004. 36(3): p. 313-5.

[81] Watson, R.A., et al., Percutaneous nephrostomy as adjunct management in advanced upper urinary tract infection. Urology, 1999. 54(2): p. 234-9.

[82] Watt, I. and J. Roylance, Pyonephrosis. Clin Radiol, 1976. 27(4): p. 513-19.

[83] Christoph, F., et al., How septic is urosepsis? Clinical course of infected hydronephrosis and therapeutic strategies. World J Urol, 2005. 23(4): p. 243-7.

[84] Kirk, D., Silent pyonephrosis as a cause of chronic ill-health. Lancet, 1982. 1(8274): p. 705-7.

[85] $\mathrm{Wu}, \mathrm{T} . \mathrm{T}$. , et al., The role of C-reactive protein and erythrocyte sedimentation rate in the diagnosis of infected hydronephrosis and pyonephrosis. J Urol, 1994. 152(1): p. 268.

[86] Subramanyam, B.R., et al., Sonography of pyonephrosis: a prospective study. AJR Am J Roentgenol, 1983. 140(5): p. 991-3.

[87] Chan, J.H., et al., MR diffusion-weighted imaging of kidney: differentiation between hydronephrosis and pyonephrosis. Clin Imaging, 2001. 25(2): p. 110-3.

[88] Baumgarten, D.A. and B.R. Baumgartner, Imaging and radiologic management of upper urinary tract infections. Urol Clin North Am, 1997. 24(3): p. 545-69.

[89] Chisena, S., [Echoguided percutaneous nephrostomy]. Arch Ital Urol Androl, 1998. 70(3): p. 133-6.

[90] Lledo Garcia, E., et al., [Initial treatment of pyonephrosis using percutaneous nephrostomy. Value of the technique]. Arch Esp Urol, 1993. 46(8): p. 711-8.

[91] Yoder, I.C., K.K. Lindfors, and R.C. Pfister, Diagnosis and treatment of pyonephrosis. Radiol Clin North Am, 1984. 22(2): p. 407-14.

[92] Li, Y. and Y. Zhang, Diagnosis and treatment of acute focal bacterial nephritis. Chin Med J (Engl), 1996. 109(2): p. 168-72.

[93] Klar, A., et al., Focal bacterial nephritis (lobar nephronia) in children. J Pediatr, 1996. 128(6): p. 850-3.

[94] Frosch, M., et al., [Acute focal bacterial nephritis in childhood]. Monatsschr Kinderheilkd, 1987. 135(12): p. 842-6.

[95] Loberant, N., et al., Acute focal bacterial nephritis in childhood brucellosis. Pediatr Radiol, 1995. 25 Suppl 1: p. S62-4.

[96] Patterson, J.E. and V.T. Andriole, Bacterial urinary tract infections in diabetes. Infect Dis Clin North Am, 1997. 11(3): p. 735-50.

[97] Qin, J.Y., [Acute focal bacterial nephritis: report of 7 cases]. Zhonghua Wai Ke Za Zhi, 1990. 28(7): p. 405-6, 445.

[98] Shinoda, G., et al., [A pediatric case of acute focal bacterial nephritis; comparison with the reports in Japanese child cases]. Kansenshogaku Zasshi, 2001. 75(11): p. 981-8.

[99] You, K., et al., [Focal infectious lesions of the renal parenchyma. Comparative contribution of echography and x-ray computed tomography]. J Radiol, 1988. 69(89): p. 509-16.

[100] Soulen, M.C., et al., Bacterial renal infection: role of CT. Radiology, 1989. 171(3): p. 7037. 
[101] Cheng, C.H., et al., Effective ultrasonographic predictor for the diagnosis of acute lobar nephronia. Pediatr Infect Dis J, 2004. 23(1): p. 11-4.

[102] Farmer, K.D., L.R. Gellett, and P.A. Dubbins, The sonographic appearance of acute focal pyelonephritis 8 years experience. Clin Radiol, 2002. 57(6): p. 483-7.

[103] Granados Molina, A., et al., [Acute lobar nephronia: Diagnosis, treatment and prognosis]. An Pediatr (Barc), 2007. 66(1): p. 84-6.

[104] Huang, J.J., et al., Acute bacterial nephritis: a clinicoradiologic correlation based on computed tomography. Am J Med, 1992. 93(3): p. 289-98.

[105] Cheng, C.H., Y.K. Tsau, and T.Y. Lin, Effective duration of antimicrobial therapy for the treatment of acute lobar nephronia. Pediatrics, 2006. 117(1): p. e84-9.

[106] Eke, N. and R.C. Echem, Chronic pyonephrosis associated with renal neovascularisation. Afr J Med Med Sci, 2004. 33(3): p. 267-9.

[107] Huland, H. and R. Busch, Chronic pyelonephritis as a cause of end stage renal disease. J Urol, 1982. 127(4): p. 642-3.

[108] Guarino, N., et al., Natural history of vesicoureteral reflux associated with kidney anomalies. Urology, 2005. 65(6): p. 1208-11.

[109] Pylkkanen, J., J. Vilska, and O. Koskimies, The value of level diagnosis of childhood urinary tract infection in predicting renal injury. Acta Paediatr Scand, 1981. 70(6): p. 879-83.

[110] Chand, D.H., et al., Incidence and severity of vesicoureteral reflux in children related to age, gender, race and diagnosis. J Urol, 2003. 170(4 Pt 2): p. 1548-50.

[111] Kohler, J.R., et al., Long-term effects of reflux nephropathy on blood pressure and renal function in adults. Nephron Clin Pract, 2003. 93(1): p. C35-46.

[112] Kohler, J., et al., Vesicoureteral reflux diagnosed in adulthood. Incidence of urinary tract infections, hypertension, proteinuria, back pain and renal calculi. Nephrol Dial Transplant, 1997. 12(12): p. 2580-7.

[113] Roberts, J.A., Mechanisms of renal damage in chronic pyelonephritis (reflux nephropathy). Curr Top Pathol, 1995. 88: p. 265-87.

[114] Braude, A.I., Current concepts of pyelonephritis. Medicine (Baltimore), 1973. 52(4): p. 257-64.

[115] Wennerstrom, M., et al., Primary and acquired renal scarring in boys and girls with urinary tract infection. J Pediatr, 2000. 136(1): p. 30-4.

[116] Tsuji, T., et al., Chronic pyelonephritis presenting as multiple tumor-like renal lesions. Intern Med, 2007. 46(12): p. 879-82.

[117] Alan, C., S. Ataus, and B. Tunc, Xanthogranulamatous pyelonephritis with psoas abscess: 2 cases and review of the literature. Int Urol Nephrol, 2004. 36(4): p. 489-93.

[118] Kawashima, A. and A.J. LeRoy, Radiologic evaluation of patients with renal infections. Infect Dis Clin North Am, 2003. 17(2): p. 433-56.

[119] Papadopoulos, G.I., et al., Chronic pyelonephritis presenting as a renal sinus tumor with retroperitoneal extension: a case report. J Med Case Reports, 2009. 3: p. 9054.

[120] Stoller, M.L. and B.A. Kogan, Sensitivity of 99mtechnetium-dimercaptosuccinic acid for the diagnosis of chronic pyelonephritis: clinical and theoretical considerations. J Urol, 1986. 135(5): p. 977-80.

[121] Craig, W.D., B.J. Wagner, and M.D. Travis, Pyelonephritis: radiologic-pathologic review. Radiographics, 2008. 28(1): p. 255-77; quiz 327-8.

[122] Chishti, A.S., et al., A guideline for the inpatient care of children with pyelonephritis. Ann Saudi Med, 2010. 30(5): p. 341-9.

[123] Michaeli, J., et al., Emphysematous pyelonephritis. J Urol, 1984. 131(2): p. 203-8. 
[124] Pontin, A.R., et al., Emphysematous pyelonephritis in diabetic patients. Br J Urol, 1995. 75(1): p. 71-4.

[125] Kelly, H.A., XI. A Preliminary Report upon the Examination of the Bladder and Catheterization of the Ureters in Men. Ann Surg, 1898. 27(1): p. 71-3.

[126] Schultz, E.H., Jr. and E.H. Klorfein, Emphysematous pyelonephritis. J Urol, 1962. 87: p. 762-6.

[127] Somani, B.K., et al., Is percutaneous drainage the new gold standard in the management of emphysematous pyelonephritis? Evidence from a systematic review. J Urol, 2008. 179(5): p. 1844-9.

[128] Shokeir, A.A., et al., Emphysematous pyelonephritis: a 15-year experience with 20 cases. Urology, 1997. 49(3): p. 343-6.

[129] Narlawar, R.S., et al., Imaging features and guided drainage in emphysematous pyelonephritis: a study of 11 cases. Clin Radiol, 2004. 59(2): p. 192-7.

[130] Huang, J.J. and C.C. Tseng, Emphysematous pyelonephritis: clinicoradiological classification, management, prognosis, and pathogenesis. Arch Intern Med, 2000. 160(6): p. 797-805.

[131] Falagas, M.E., et al., Risk factors for mortality in patients with emphysematous pyelonephritis: a meta-analysis. J Urol, 2007. 178(3 Pt 1): p. 880-5; quiz 1129.

[132] Khaira, A., et al., Retrospective analysis of clinical profile prognostic factors and outcomes of 19 patients of emphysematous pyelonephritis. Int Urol Nephrol, 2009. 41(4): p. 959-66.

[133] Wan, Y.L., et al., Acute gas-producing bacterial renal infection: correlation between imaging findings and clinical outcome. Radiology, 1996. 198(2): p. 433-8.

[134] Ubee, S.S., L. McGlynn, and M. Fordham, Emphysematous pyelonephritis. BJU Int, 2010.

[135] Tang, H.J., et al., Clinical characteristics of emphysematous pyelonephritis. J Microbiol Immunol Infect, 2001. 34(2): p. 125-30.

[136] Abdul-Halim, H., et al., Severe emphysematous pyelonephritis in diabetic patients: diagnosis and aspects of surgical management. Urol Int, 2005. 75(2): p. 123-8.

[137] Kuo, Y.T., et al., Emphysematous pyelonephritis: imaging diagnosis and follow-up. Kaohsiung J Med Sci, 1999. 15(3): p. 159-70.

[138] Wan, Y.L., et al., Predictors of outcome in emphysematous pyelonephritis. J Urol, 1998. 159(2): p. 369-73.

[139] Ahlering, T.E., et al., Emphysematous pyelonephritis: a 5-year experience with 13 patients. J Urol, 1985. 134(6): p. 1086-8.

[140] Hudson, M.A., et al., Emphysematous pyelonephritis: successful management by percutaneous drainage. J Urol, 1986. 136(4): p. 884-6.

[141] Chen, M.T., et al., Percutaneous drainage in the treatment of emphysematous pyelonephritis: 10-year experience. J Urol, 1997. 157(5): p. 1569-73.

[142] Bauman, N., et al., Laparoscopic nephrectomy for emphysematous pyelonephritis. Can J Urol, 2005. 12(4): p. 2764-8.

[143] Parsons, M.A., et al., Xanthogranulomatous pyelonephritis: a pathological, clinical and aetiological analysis of 87 cases. Diagn Histopathol, 1983. 6(3-4): p. 203-19.

[144] Izzidien, A.Y., et al., Xanthogranulomatous pyelonephritis in childhood. J Pediatr Surg, 1980. 15(5): p. 686-9.

[145] Sugie, S., et al., Fine-needle aspiration cytology of xanthogranulomatous pyelonephritis. Urology, 1991. 37(4): p. 376-9. 
[146] Youngson, G.G. and E.S. Gray, Neonatal xanthogranulomatous pyelonephritis. Br J Urol, 1990. 65(5): p. 541-2.

[147] Malek, R.S. and J.S. Elder, Xanthogranulomatous pyelonephritis: a critical analysis of 26 cases and of the literature. J Urol, 1978. 119(5): p. 589-93.

[148] Schoborg, T.W., et al., Xanthogranulomatous pyelonephritis associated with renal carcinoma. J Urol, 1980. 124(1): p. 125-27.

[149] Gregg, C.R., T.E. Rogers, and R.S. Munford, Xanthogranulomatous pyelonephritis. Curr Clin Top Infect Dis, 1999. 19: p. 287-304.

[150] Levy, M., R. Baumal, and A.A. Eddy, Xanthogranulomatous pyelonephritis in children. Etiology, pathogenesis, clinical and radiologic features, and management. Clin Pediatr (Phila), 1994. 33(6): p. 360-6.

[151] Chuang, C.K., et al., Xanthogranulomatous pyelonephritis: experience in 36 cases. J Urol, 1992. 147(2): p. 333-6.

[152] Nataluk, E.A., D.L. McCullough, and E.O. Scharling, Xanthogranulomatous pyelonephritis, the gatekeeper's dilemma: a contemporary look at an old problem. Urology, 1995. 45(3): p. 377-80.

[153] Grainger, R.G., A.J. Longstaff, and M.A. Parsons, Xanthogranulomatous pyelonephritis: a reappraisal. Lancet, 1982. 1(8286): p. 1398-401.

[154] Eastham, J., T. Ahlering, and E. Skinner, Xanthogranulomatous pyelonephritis: clinical findings and surgical considerations. Urology, 1994. 43(3): p. 295-9.

[155] Zugor, V., G.E. Schott, and A.P. Labanaris, Xanthogranulomatous pyelonephritis in childhood: a critical analysis of 10 cases and of the literature. Urology, 2007. 70(1): p. 157-60.

[156] McDonald, G.S., Xanthogranulomatous pyelonephritis. J Pathol, 1981. 133(3): p. 203-13.

[157] Tolia, B.M., et al., Xanthogranulomatous pyelonephritis: detailed analysis of 29 cases and a brief discussion of atypical presentations. J Urol, 1981. 126(4): p. 437-42.

[158] Gupta, S., C.E. Araya, and V.R. Dharnidharka, Xanthogranulomatous pyelonephritis in pediatric patients: case report and review of literature. J Pediatr Urol, 2010. 6(4): p. 355-8.

[159] Korkes, F., et al., Xanthogranulomatous pyelonephritis: clinical experience with 41 cases. Urology, 2008. 71(2): p. 178-80.

[160] Hartman, D.S., et al., Xanthogranulomatous pyelonephritis: sonographic--pathologic correlation of 16 cases. J Ultrasound Med, 1984. 3(11): p. 481-8.

[161] Demertzis, J. and C.O. Menias, State of the art: imaging of renal infections. Emerg Radiol, 2007. 14(1): p. 13-22.

[162] Hertle, L., et al., Computed tomography in xanthogranulomatous pyelonephritis. Eur Urol, 1984. 10(6): p. 385-8.

[163] Goldman, S.M., et al., CT of xanthogranulomatous pyelonephritis: radiologicpathologic correlation. AJR Am J Roentgenol, 1984. 142(5): p. 963-9.

[164] Soler, R., et al., Focal xanthogranulomatous pyelonephritis in a teenager: MR and CT findings. Eur J Radiol, 1997. 24(1): p. 77-9.

[165] Brown, P.S., Jr., M. Dodson, and P.S. Weintrub, Xanthogranulomatous pyelonephritis: report of nonsurgical management of a case and review of the literature. Clin Infect Dis, 1996. 22(2): p. 308-14.

[166] Tsai, K.H., et al., Bilateral xanthogranulomatous pyelonephritis. J Chin Med Assoc, 2008. 71(6): p. 310-4.

[167] Tobias-Machado, M., et al., Laparoscopic nephrectomy in inflammatory renal disease: proposal for a staged approach. Int Braz J Urol, 2005. 31(1): p. 22-8. 
[168] Stanton, M.J. and W. Maxted, Malacoplakia: a study of the literature and current concepts of pathogenesis, diagnosis and treatment. J Urol, 1981. 125(2): p. 139-46.

[169] Dobyan, D.C., L.D. Truong, and G. Eknoyan, Renal malacoplakia reappraised. Am J Kidney Dis, 1993. 22(2): p. 243-52.

[170] van Crevel, R., et al., Functional and morphological monocyte abnormalities in a patient with malakoplakia. Am J Med, 1998. 105(1): p. 74-7.

[171] Esparza, A.R., et al., Renal parenchymal malakoplakia. Histologic spectrum and its relationship to megalocytic interstitial nephritis and xanthogranulomatous pyelonephritis. Am J Surg Pathol, 1989. 13(3): p. 225-36.

[172] Callea, F., B. Van Damme, and V.J. Desmet, Alpha-1-antitrypsin in malakoplakia. Virchows Arch A Pathol Anat Histol, 1982. 395(1): p. 1-9.

[173] Sanchez, L.M., S.I. Sanchez, and J.L. Bailey, Malacoplakia presenting with obstructive nephropathy with bilateral ureter involvement. Nat Rev Nephrol, 2009. 5(7): p. 41822.

[174] Ozkurkcugil, C., et al., A case of renal parenchymal malacoplakia with bilateral pulmonary lesions. Br J Urol, 1996. 77(1): p. 159-60.

[175] Koroku, M., et al., [Malacoplakia in the ureter and bladder]. Hinyokika Kiyo, 2005. 51(3): p. 183-5.

[176] Tam, V.K., et al., Renal parenchymal malacoplakia: a rare cause of ARF with a review of recent literature. Am J Kidney Dis, 2003. 41(6): p. E13-7.

[177] Yang, A.H., et al., Post-infectious glomerulonephritis in a patient with vesicorenal malacoplakia--coincidence or causal relationship? Nephrol Dial Transplant, 2000. 15(7): p. 1060-2.

[178] Sheerin, N.S., K.F. Bhatacharia, and M.C. Webb, Positron emission tomography in a patient with renal malacoplakia. Am J Kidney Dis, 2003. 42(3): p. E36-9.

[179] Velasquez Lopez, J.G., A. Velez Hoyos, and J.F. Uribe Arcila, [Malakoplakia in urology: six cases report and review of the literature]. Actas Urol Esp, 2006. 30(6): p. 610-8.

[180] Venkatesh, S.K., N. Mehrotra, and R.B. Gujral, Sonographic findings in renal parenchymal malacoplakia. J Clin Ultrasound, 2000. 28(7): p. 353-7.

[181] Mitchell, M.A., et al., Bilateral renal parenchymal malacoplakia presenting as fever of unknown origin: case report and review. Clin Infect Dis, 1994. 18(5): p. 704-18.

[182] Houston, T.K., 2nd, et al., Gallium-67-citrate scanning of renal parenchymal malacoplakia. J Nucl Med, 1998. 39(8): p. 1454-7.

[183] Trillo, A., W.B. Lorentz, and N.O. Whitley, Malakoplakia of kidney simulating renal neoplasm. Urology, 1977. 10(5): p. 472-7.

[184] Evans, N.L., J. French, and M.B. Rose, Renal malacoplakia: an important consideration in the differential diagnosis of renal masses in the presence of Escherichia coli infection. Br J Radiol, 1998. 71(850): p. 1083-5.

[185] Dohle, G.R., J. Zwartendijk, and J.H. Van Krieken, Urogenital malacoplakia treated with fluoroquinolones. J Urol, 1993. 150(5 Pt 1): p. 1518-20.

[186] Dasgupta, P., et al., Malacoplakia: von Hansemann's disease. BJU Int, 1999. 84(4): p. 464-9. 


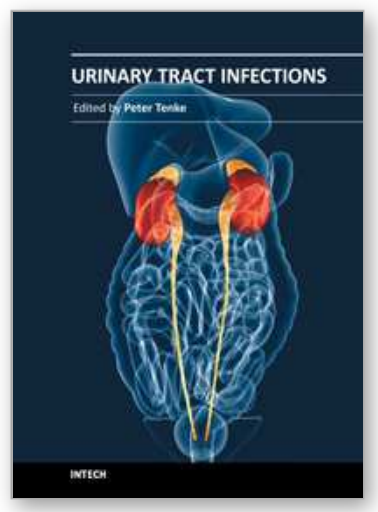

\author{
Urinary Tract Infections \\ Edited by Dr. Peter Tenke
}

ISBN 978-953-307-757-4

Hard cover, 360 pages

Publisher InTech

Published online 30, September, 2011

Published in print edition September, 2011

Urinary tract infections (UTIs) are among the most common bacterial infections worldwide, and they are also the leading cause of hospital-acquired infections. Therefore, the appropriate management of UTIs is a major medical and financial issue. This book covers different clinical manifestations of UTI, with special emphasis on some hard-to-treat diseases, and special conditions in respect of treatment; antibiotic resistance and the available alternative strategies for the prevention and treatment of UTIs and it deals with urinary tract infections in children. The aim of this book is to give a summary about the different aspects of the diagnosis, management and prevention of urinary tract infections for all medical disciplines.

\title{
How to reference
}

In order to correctly reference this scholarly work, feel free to copy and paste the following:

Nasser Shakhssalim, Mohammad Samzadeh and Seyed Mohammad Ghahestani (2011). Complicated Upper Urinary Tract Infection, Urinary Tract Infections, Dr. Peter Tenke (Ed.), ISBN: 978-953-307-757-4, InTech, Available from: http://www.intechopen.com/books/urinary-tract-infections/complicated-upper-urinary-tractinfection

\section{INTECH}

open science | open minds

\section{InTech Europe}

University Campus STeP Ri Slavka Krautzeka 83/A 51000 Rijeka, Croatia

Phone: +385 (51) 770447

Fax: +385 (51) 686166 www.intechopen.com

\section{InTech China}

Unit 405, Office Block, Hotel Equatorial Shanghai No.65, Yan An Road (West), Shanghai, 200040, China 中国上海市延安西路65号上海国际贵都大饭店办公楼 405 单元 Phone: +86-21-62489820

Fax: $+86-21-62489821$ 
(C) 2011 The Author(s). Licensee IntechOpen. This chapter is distributed under the terms of the Creative Commons Attribution-NonCommercialShareAlike-3.0 License, which permits use, distribution and reproduction for non-commercial purposes, provided the original is properly cited and derivative works building on this content are distributed under the same license. 